\title{
The cycling of iron, zinc and cadmium in the North East Pacific Ocean - insights from stable isotopes
}

\author{
Tim M. Conway ${ }^{1,2, *}$ and Seth G. John ${ }^{1,3}$ \\ ${ }^{1}$ Department of Earth and Ocean Sciences, University of South Carolina, Columbia, SC 29208 USA \\ ${ }^{2}$ Institute of Geochemistry and Petrology, Department of Earth Sciences, Clausiusstrasse 25, 8092 Zürich, \\ Switzerland (Present address) \\ ${ }^{3}$ Department of Earth Sciences, University of Southern California, Los Angeles, CA 90089 USA (Present \\ address)
}

*Corresponding author: conway.tm@gmail.com; Phone: Tel: +41 446324797

Keywords: GEOTRACES, biogeochemical cycles, sediments, trace metals, oxygen minimum zones

(C) 2015. This manuscript version is made available under the Elsevier user license http://www.elsevier.com/open-access/userlicense/1.0/ 


\section{Abstract}

3 Dissolved stable isotope ratios of the transition metals provide useful information, both

4 for understanding the cycling of these bioactive trace elements through the oceans, and

5 tracing their marine sources and sinks. Here, we present seawater dissolved $\mathrm{Fe}, \mathrm{Zn}$ and

$6 \mathrm{Cd}$ concentration and stable isotope ratio $\left(\delta^{56} \mathrm{Fe}, \delta^{66} \mathrm{Zn}\right.$, and $\left.\delta^{114} \mathrm{Cd}\right)$ profiles from two

7 stations in the Pacific Ocean, the SAFe Station $\left(30^{\circ} \mathrm{N} 140^{\circ} \mathrm{W}\right)$ in the subtropical North

8 East Pacific from the GEOTRACES IC2 cruise, and the marginal San Pedro Basin

$9\left(33.8^{\circ} \mathrm{N} 118.4^{\circ} \mathrm{W}\right)$ within the South California Bight. These data represent, to our

10 knowledge, the first full-water column profiles for $\delta^{66} \mathrm{Zn}$ and $\delta^{56} \mathrm{Fe}$ from the open-ocean

11 North Pacific, and the first observations of dissolved $\delta^{66} \mathrm{Zn}$ and $\delta^{114} \mathrm{Cd}$ in a low-oxygen

12 marginal basin. At the SAFe station, $\delta^{56} \mathrm{Fe}$ is isotopically lighter throughout the water

13 column (-0.6 to $+0.1 \%$, relative to IRRM-014) compared to the North Atlantic,

14 suggesting significant differences in Fe sources or Fe cycling between these two ocean

15 basins. A broad minimum in $\delta^{56} \mathrm{Fe}$ associated with the North Pacific oxygen minimum

16 zone (OMZ; <75 $\mu \mathrm{mol} \mathrm{kg}^{-1}$ dissolved oxygen; 550-2000 m depth) is consistent with

17 reductive sediments along the California margin being an important source of dissolved

18 Fe to the North Pacific. Other processes which may influence $\delta^{56} \mathrm{Fe}$ at SAFe include

19 biological cycling in the upper ocean, and input of Fe from hydrothermal vents and oxic

20 sediments below the $\mathrm{OMZ}$. $\mathrm{Zn}$ and $\mathrm{Cd}$ concentration profiles at both stations closely

21 match the distribution of the macronutrients silicate and phosphate, respectively. At

$22 \mathrm{SAFe}, \delta^{114} \mathrm{Cd}$ increases towards the surface, reflecting the biological preference for

23 assimilation of lighter $\mathrm{Cd}$ isotopes, while negative $\mathrm{Cd}^{*}(-0.12)$ associated with low

24 oxygen waters supports the recently proposed hypothesis of water-column $\mathrm{CdS}$

25 precipitation. In contrast to $\delta^{114} \mathrm{Cd}, \delta^{66} \mathrm{Zn}$ at $\mathrm{SAFe}$ decrease towards the surface ocean,

26 perhaps due to scavenging of isotopically heavy $\mathrm{Zn}$, while at intermediate depths $\delta^{66} \mathrm{Zn}$

27 provides further evidence of a mid-depth dissolved $\delta^{66} \mathrm{Zn}$ maximum. We suggest this may

28 be a global feature of Zn biogeochemistry related to either to regeneration of heavy

29 adsorbed $\mathrm{Zn}$, or to $\mathrm{ZnS}$ formation and removal within the water column. Data from San

30 Pedro shows that anoxic sediments can be a source of isotopically light $\mathrm{Zn}$ to the water

31 column ( $\delta^{66} \mathrm{Zn}$ of $\sim-0.3 \%$ o relative to JMC Lyon), though evidence of this signal is not 
32 observed being transported to SAFe. Within North Pacific Intermediate Water at SAFe

33 (NPIW; 500 m) elevated $\mathrm{Cd}^{*}$ and $\mathrm{Zn}^{*}$ and a focused minimum in $\delta^{56} \mathrm{Fe}$ suggest possible

34 transport of $\mathrm{Fe}, \mathrm{Zn}$, and $\mathrm{Cd}$ over thousands of $\mathrm{km}$ from subpolar waters, meaning that

35 NPIW may have a strong influence on the subsurface distribution of trace metals

36 throughout the North Pacific.

\section{Introduction}

40 Measurements of the stable isotope ratios of the transition metals are becoming useful 41 oceanographic tools for study of the marine biogeochemical cycling of these trace metals.

42 There is great interest in understanding the cycling of trace metals such as $\mathrm{Fe}, \mathrm{Cu}, \mathrm{Ni}, \mathrm{Zn}$ 43 and $\mathrm{Cd}$ because of their roles as essential nutrients, or in some cases toxins, for marine 44 phytoplankton. Their role in phytoplankton physiology means that trace metals ultimately 45 influence primary productivity and the global carbon cycle (e.g. Morel and Price, 2003).

46 Over the last 5-10 years, a combination of advances in chemical purification techniques,

47 higher-resolution mass spectrometers and the onset of the International GEOTRACES 48 program have facilitated the measurement of isotopic ratios of $\mathrm{Fe}\left(\delta^{56} \mathrm{Fe}\right), \mathrm{Cu}\left(\delta^{65} \mathrm{Cu}\right), \mathrm{Ni}$ $49\left(\delta^{60} \mathrm{Ni}\right), \mathrm{Zn}\left(\delta^{66} \mathrm{Zn}\right)$ and $\mathrm{Cd}\left(\delta^{114} \mathrm{Cd} ; \varepsilon^{114} \mathrm{Cd} ; \varepsilon^{112} \mathrm{Cd}\right)$ dissolved in seawater. The first 50 studies have shown that these ratios can be determined in seawater with sufficient 51 precision and accuracy to observe variability at the permil level, even at the low 52 concentrations of these metals in surface seawater (Bermin et al., 2006; Lacan et al., 53 2006; Ripperger and Rehkämper, 2007; Lacan et al., 2008; Cameron and Vance, 2014).

54 In the last few years, the first multiple-profile studies and oceanographic sections of $55 \delta^{56} \mathrm{Fe}, \delta^{66} \mathrm{Zn}$ and $\delta^{114} \mathrm{Cd}$ are beginning to appear as part of efforts such as the 56 GEOTRACES program (e.g. Radic et al., 2011; Boyle et al.; 2012; Abouchami et al., 57 2014; Conway and John, 2014a; 2014b; 2015; Labatut et al., 2014; Zhao et al., 2014).

59 Combined with concentration data, stable isotope ratios of $\mathrm{Fe}, \mathrm{Zn}$ and $\mathrm{Cd}$ provide 60 valuable new information that can be used to investigate and understand the marine 61 sources, cycling and sinks of these elements in a way that is not possible from 62 concentration data alone. For example, studies have shown that different Fe sources have 
63 different $\delta^{56} \mathrm{Fe}$ signatures, dependent on different chemical and biogeochemical 64 processes, and that these $\delta^{56} \mathrm{Fe}$ signatures persist great distances through the ocean.

65 Reduced $\mathrm{Fe}$ released to the water column from low-oxygen pore waters in benthic 66 sediments is characterized by very light $\delta^{56} \mathrm{Fe}$ values of -1.8 to $-3.5 \%$ o (e.g. Homoky et 67 al., 2009; John et al., 2012; Severmann et al., 2010), while non-reductive Fe release from 68 sediments and particles has been suggested to be 0 to $+0.2 \%$ o heavier than crustal values 69 of $+0.09 \%$ o (Radic et al., 2011; Homoky et al., 2013; Conway and John, 2014a; Labatut 70 et al., 2014). Recently, the $\delta^{56} \mathrm{Fe}$ signature of Fe released from atmospheric dust was 71 hypothesized to be much heavier $\left(+0.68 \%\right.$ ) than bulk natural crustal aerosol $\delta^{56} \mathrm{Fe}$ 72 ( +0.1\%; Beard et al., 2003; Conway and John, 2014a; Waeles et al., 2007), attributed to 73 fractionation reactions upon dissolution in seawater, perhaps involving heavier Fe bound 74 to organic ligands (John and Adkins, 2012; Conway and John, 2014a; Diderikson et al., 75 2008; Morgan et al., 2010).

77 Hydrothermal $\mathrm{Fe}$ signatures are likely to depend on the vent chemistry and redox 78 processes controlling distribution of $\mathrm{Fe}$ away from the vent (Severmann et al., 2004; 79 Bennett et al., 2009). Very light hydrothermal dissolved $\delta^{56} \mathrm{Fe}$ signatures have been 80 recently documented within a hydrothermal plume at the Mid-Atlantic Ridge in the North 81 Atlantic (-1.35\% ; Conway and John, 2014a). Here, oxide precipitation is thought to 82 dominate the system, resulting in dissolved $\delta^{56} \mathrm{Fe}$ lighter than the vent fluids (Severmann 83 et al., 2004; Conway and John, 2014a), but the net signature of release from other vents 84 where sulfur chemistry is relatively more important could be heavy. Recent work has 85 shown variable $\delta^{56} \mathrm{Fe}$ signatures for distal hydrothermal signals in the Pacific Ocean, with 86 the $\delta^{56} \mathrm{Fe}$ of a hydrothermal $\mathrm{Fe}$ anomaly attributed to a distal EPR in the South Pacific 87 ranging from -0.6 to $+0.5 \%$ o (Fitzsimmons et al., 2013; Fitzsimmons et al., 2014). A 88 recent study of a submarine volcano close to New Zealand showed a hydrothermal $\delta^{56} \mathrm{Fe}$ 89 signal that evolved from $+0.1 \%$ o to $+1.7 \%$ as Fe precipitated close to the vent (Ellwood $e t$ 90 al., 2015), suggesting that the distal signal from this system could be remarkably heavy. 91 However, despite these continuing uncertainties over hydrothermal source signals, we 92 recently showed that it is possible to use $\delta^{56} \mathrm{Fe}$ measurements to trace $\mathrm{Fe}$ sources over 93 long distances and thus constrain the importance of different Fe sources across a North 
94 Atlantic section (Conway and John, 2014a). The short marine residence of time of Fe,

95 compared to other trace metals may also lead to significant inter-oceanic differences in

$96 \delta^{56} \mathrm{Fe}$ (Beard et al., 2003), which means that $\delta^{56} \mathrm{Fe}$ can provide valuable information on

97 the dominant $\mathrm{Fe}$ sources in each region.

99 Seawater-dissolved $\delta^{66} \mathrm{Zn}$ measurements show promise for being able to understand the 100 importance of processes such as scavenging, uptake and regeneration for the marine $\mathrm{Zn}$

101 cycle, as well as for understanding the global ocean mass balance of Zinc (Conway and 102 John, 2014b; Little et al., 2014; Zhao et al., 2014), while dissolved $\delta^{114} \mathrm{Cd}$ provide 103 important insights about biological and physical cycling of $\mathrm{Cd}$ in the oceans (Ripperger $e t$ 104 al., 2007). Phytoplankton are thought to preferentially acquire the light isotopes of $\mathrm{Zn}$ 105 and $\mathrm{Cd}$, while scavenging preferentially adsorbs heavy $\mathrm{Zn}$ isotopes to organic matter 106 (Lacan et al., 2006; John, et al., 2007a; Horner et al., 2013; John and Conway, 2014). In 107 contrast to $\mathrm{Zn}, \mathrm{Cd}$ is not thought to be scavenged to organic matter (John and Conway, 108 2014). Biological uptake of $\mathrm{Zn}$ and $\mathrm{Cd}$ therefore drive the resultant surface dissolved pool 109 to heavier isotope ratios, while scavenging of $\mathrm{Zn}$ has the opposite effect on $\delta^{66} \mathrm{Zn}$ (John 110 and Conway, 2014). Isotopic ratios of both elements therefore provide information on the 111 relative importance of different processes to the surface ocean cycling of these elements, 112 and how this varies across the surface oceans. Fractionation of $\delta^{114} \mathrm{Cd}$ due to biological 113 uptake and incomplete regeneration in surface waters may lead to different preformed $114 \delta^{114} \mathrm{Cd}$ signatures in different water masses, allowing investigation of the large scale 115 cycling of Cd (Xue et al., 2013; Abouchami et al., 2014; Conway and John, 2015). Both 116 elements have relatively homogenous signatures in the global deep oceans $\left(\delta^{114} \mathrm{Cd}+0.2\right.$ 117 to +0.3 and $\delta^{66} \mathrm{Zn}+0.5 \%$ ), which are heavier than the isotopic signatures of their known 118 sources $(+0.1 \%$ o for $\mathrm{Cd} ;+0.1$ to $+0.3 \%$ o for $\mathrm{Zn})$, pointing to as-yet-unconstrained light 119 sinks for both metals (Rehkämper et al., 2012; Little et al., 2014; Janssen et al., 2014; 120 and references therein). One such sink may take the form of light biogenic $\mathrm{Zn}$ and/or $\mathrm{Zn}$ 121 and Cd sulfides, precipitated directly within the water column (Conway and John, 2014b; 122 2015; Janssen et al., 2014, Janssen and Cullen, 2015). 
124 Despite the community interest in these new tracers, the challenges of collection and 125 analysis mean that there is still little coverage to date in much of the world's oceans,

126 especially in the Pacific Ocean. Historically, the North East Pacific was the focus of some 127 of the first accurate studies of trace elements in the late 1970s - early 1980s, which 128 demonstrated the now widely accepted oceanic relationships between $\mathrm{Cd} /$ phosphate and $129 \mathrm{Zn} /$ silicate, as well as Fe's role as a key limiting nutrient (Bruland et al., 1978a; 1978b

130 Bruland, 1980; Coale et al., 1996). To date, the only North Pacific $\delta^{56} \mathrm{Fe}$ data is from two

131 marginal basins close to California and equatorial waters near Papua New Guinea (Radic 132 et al., 2011; John et al., 2012; Labatut et al., 2014). $\delta^{66} \mathrm{Zn}$ measurements are limited to 133 two published $\mathrm{Zn}$ profiles above $1000 \mathrm{~m}$ (Bermin et al., 2006; John, 2007), and $\delta^{114} \mathrm{Cd}$ is 134 so far restricted to two profiles by Ripperger et al. (2007), although conference abstracts 135 suggest a number of studies are in progress (e.g. Vance et al., 2012).

137 In this study, we present paired $\mathrm{Fe}, \mathrm{Zn}$ and $\mathrm{Cd}$ isotope ratio and concentration profiles 138 from two locations in the North East Pacific (Fig. 1), the open-ocean SAFe station $\left(30^{\circ} \mathrm{N}\right.$ $\left.139140^{\circ} \mathrm{W}\right)$, and the restricted San Pedro basin on the Californian Margin $\left(33.8^{\circ} \mathrm{N} 118.4^{\circ} \mathrm{W}\right)$ 140 that was previously studied for $\delta^{56} \mathrm{Fe}$ by John et al. (2012). Using this data we: 1) discuss 141 the sources and cycling of Fe and $\delta^{56} \mathrm{Fe}$ in the open N. E. Pacific Ocean, 2) use $\mathrm{Cd}, \mathrm{Cd}^{*}$ 142 and $\delta^{114} \mathrm{Cd}$ to provide more insight into how biological uptake/regeneration, physical 143 circulation and sulfide precipitation control dissolved $\mathrm{Cd}$ and $\delta^{114} \mathrm{Cd}$ distributions, and 3) 144 use $\delta^{66} \mathrm{Zn}$ and $\mathrm{Zn} *$ data to investigate both how scavenging/regeneration of adsorbed $\mathrm{Zn}$ 145 and/or sulfide precipitation may influence the distribution of dissolved $\mathrm{Zn}$ and how 146 margin sediments can supply dissolved $\mathrm{Zn}$ to the ocean.

\section{Methods}

\subsection{Seawater Sampling and Oceanographic Setting}

152 A 12-depth seawater profile was collected from the SAFe site $\left(30^{\circ} \mathrm{N} 140^{\circ} \mathrm{W}\right)$ in the North 153 Pacific as part of a trace metal isotope cast (GT event 2066) on May $17^{\text {th }} 2009$, during the 154 US GEOTRACES IC2 inter-comparison cruise. Seawater was collected by the onboard 
155 sampling team using the GEOTRACES rosette and filtered with a $0.2 \mu \mathrm{m}$ Osmonics 156 capsule filter into acid-cleaned $1 \mathrm{~L}$ polyethylene bottles, according to published 157 techniques (Cutter and Bruland, 2012). Seawater samples were collected from the San

158 Pedro basin on the California Margin on board two cruises in September and October 1592008 as part of the San Pedro Ocean Time Series (SPOT) program (John et al., 2012). 160 San Pedro water samples were collected using 5 L Teflon-coated Niskin bottles mounted 161 on a powder coated Rosette, or a Niskin bottle mounted on the ship's CTD rosette frame 162 which was triggered during the downcast to minimize contamination (895 m only), and 163 filtered through $0.4 \mu \mathrm{m}$ Pall polyethersulfone filters (John et al., 2012). All filtered 164 seawater samples were later acidified to $\mathrm{pH} \sim 2$ by addition of $1 \mathrm{~mL} 12 \mathrm{M}$ QD-HCl and 165 left for several years before processing and analysis of dissolved $\mathrm{Fe}, \mathrm{Zn}$ and $\mathrm{Cd}$ 166 concentrations and stable isotope ratios. The San Pedro samples used in this study were 167 previously sub-sampled and analysed for dissolved $\mathrm{Fe}$ and $\delta^{56} \mathrm{Fe}$ (John et al. 2012), and 168 we do not present new Fe data for these here.

170 The SAFe station is located in the open North East Pacific Ocean $\left(140^{\circ} \mathrm{W}, 30^{\circ} \mathrm{N}\right.$; Fig. 1), 171 away from proximal sources of trace metals. The station is around $\sim 1900 \mathrm{~km}$ from the 172 nearest continental shelf (California) or the nearest known hydrothermal sources (Juan de 173 Fuca ridge and Loihi, Hawaii; Fig. 1). Atmospheric dust supply to this region is relatively 174 low (0.2-0.5 $\mathrm{g} \mathrm{m}^{-2} \mathrm{yr}^{-1}$; Jickells et al., 2005). The distribution of trace metals in the water175 column at this location are most strongly influenced by biological activity and in situ 176 processes in surface waters $(<500 \mathrm{~m})$, transport of metals by large-scale ocean 177 circulation, and the presence of a pronounced oxygen minimum zone at depths of $\sim 550$ $1782000 \mathrm{~m}$ (Figs 2-3). The T-S water mass structure in this area of the North Pacific is well 179 defined by Talley and coworkers and we follow their descriptions of the major water 180 mass end-members (Talley, 2008; Talley et al., 2011). The subsurface water-mass 181 structure (Figs. 2-3) consists of North Pacific Intermediate Water (NPIW; 300-600 m; 182 26.7-26.9 $\left.\sigma_{\theta}\right)$, Antarctic Intermediate Water (AAIW) mixed with NPIW ( 600-1300 m; 183 26.9-27.6 $\sigma_{\theta}$, salinity 34.14-34.45). Below this, Pacific Deep Water and modified Upper 184 Circumpolar Deep Water (PDW \&UCDW; <34.69, 1300-3800 m, 1.1-1.2 ${ }^{\circ} \mathrm{C}$,) and 185 Lower Circumpolar (LCDW; >3800 m, >34.69 p.s.u.;) are most important. NPIW is also 
186 characterized by a pronounced salinity minimum (<34.14 p.s.u.), reflecting its origins in

187 subpolar waters in the Sea of Okhotsk, a northern marginal sea located between Siberia 188 and Kamchatka, with transport from Asia via the Kuroshio currents (Talley, 1993; Talley 189 et al., 2011).

191 The San Pedro basin, located within the South California Bight on the Californian Margin 192 ( 900 $\mathrm{m}$ deep; $33.8^{\circ} \mathrm{N} 118.4^{\circ} \mathrm{W}$; Fig. 1), is a silled basin with a flat bottom, surrounded 193 by broad shallow shelves (0-100 m) and characterized by low dissolved oxygen (John et 194 al., 2012). The basin is silled below $740 \mathrm{~m}$. Fully anoxic sediments with pore-water 195 dissolved $\mathrm{Fe}$ concentrations up to $100 \mu \mathrm{mol} \mathrm{L} \mathrm{L}^{-1}$, combined with dissolved oxygen 196 concentrations as low as $2-5 \mu \mathrm{mol} \mathrm{L^{-1 }}$ in overlying waters lead to dissolved $\mathrm{Fe}$ 197 concentrations as high as $7.3 \mathrm{nmol} \mathrm{L}^{-1}$ within the water column (Severmann et al., 2010; 198 John et al., 2012). John et al. (2012) interpreted high dissolved Fe concentrations and 199 isotopically light $\delta^{56} \mathrm{Fe}$ throughout the water-column as reflecting the input of isotopically 200 light Fe(II) from benthic sediments. At shallow depths (50-100 m), lower-salinity, cold 201 water indicates the subsurface presence of the California Current that moves south along 202 the coast (Lynn and Simpson, 1987; Talley et al., 2011). Ekman transport and eddies 203 provide variable upwelling of nutrients and trace metals from the benthic boundary layers 204 to the California Current system along the Washington-Californian margin (e.g. Biller 205 and Bruland, 2014; King and Barbeau, 2011). Localised eddy upwelling of Fe from shelf 206 sediments can lead to dissolved Fe concentrations up to $8 \mathrm{nmol} \mathrm{kg}^{-1}$ in surface waters 207 close to the Californian coast and islands (King and Barbeau, 2011). Deeper in the water 208 column at San Pedro, at 150-200 m, the Californian Undercurrent moves northwards 209 along the Californian margin from the Baja California (Talley et al., 2011). The San 210 Pedro basin water column can therefore be thought of in terms of in situ vertical 211 processes throughout the water column, as well as lateral advection in surface waters $212<200 \mathrm{~m}$.

213

$214 \quad 2.2$ Sample Processing and Analysis 
216 All seawater samples were processed at the University of South Carolina (USC) in flow 217 benches under ULPA filtration, all water used was ultrapure (>18.2 M 2$)$ and all acids 218 and reagents were Aristar Ultra ${ }^{\mathrm{TM}}$ obtained from VWR International. Dissolved Fe, Zn 219 and $\mathrm{Cd}$ concentrations and stable isotope ratios were determined by Thermo Neptune 220 MC-ICPMS with Jet interface in the Center for Elemental Mass Spectrometry at USC 221 using isotope dilution and the double-spike technique. Samples were analyzed following 222 extraction of metals from seawater with Nobias PA1 resin and purification with AGMP-1

223 anion exchange chromatography. The methodology used in this study, as well as the 224 excellent precision and accuracy for isotopes ratios obtained by this technique, have 225 already been described at some length (Conway et al., 2013; Conway and John, 2014a;

226 2014b; 2015), and so will not be discussed in detail here. We also previously 227 demonstrated that dissolved concentration measurements made using this method agree 228 well with the most recent (May 2013) consensus values for SAFe seawater standards 229 (Conway et al., 2013).

230

231 We express all stable isotope ratios in delta notation, relative to international isotope 232 standards:

233

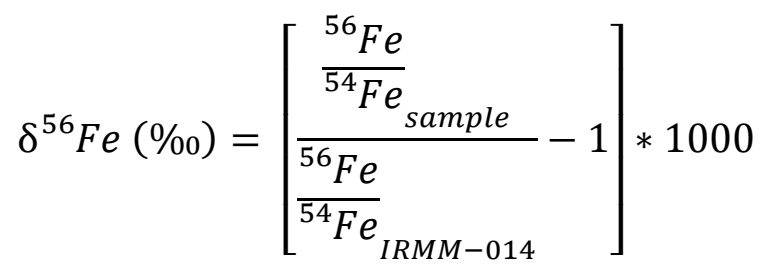

234

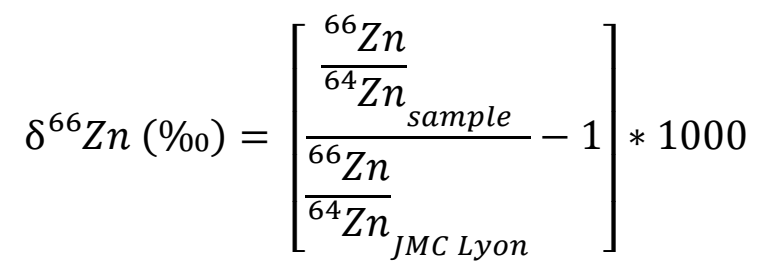

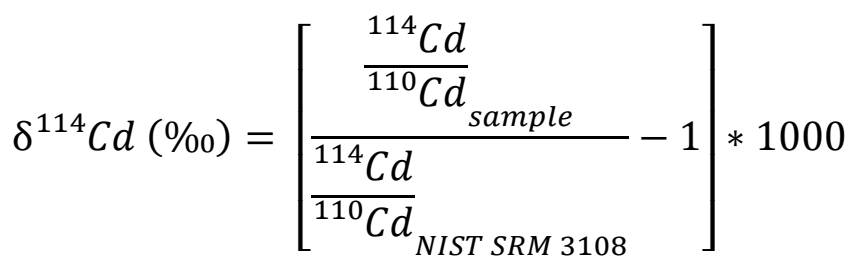


237 For $\delta^{66} \mathrm{Zn}$, all samples were measured relative to NIST SRM $682 \mathrm{Zn}$ and then are 238 expressed relative to JMC Lyon by adjustment by $-2.46 \%$ based on repeated analysis of 239 the separation between the two standards (Conway et al., 2013; Conway and John, 240 2014b). Metal from each $1 \mathrm{~L}$ sample was measured twice by MC-ICPMS for each 241 element, and the mean values are shown in figures. Following a detailed discussion of 242 uncertainties affecting double spike ICP-MS measurements obtained with this procedure, 243 and the repeated observation that total uncertainty is dominated by internal error (John, 244 2012; Conway et al., 2013), we express $2 \sigma$ uncertainty on all stable isotope 245 measurements as the combined standard internal error of samples and bracketing isotope 246 standards. Equally, for dissolved elemental concentrations, we follow Conway et al. 247 (2013) and apply 2\% uncertainty to account for weighing, pipetting and calibration 248 uncertainties.

250 For isotope mass balance calculations in Sections 3.1.2 and 3.4, we use a simple two251 component isotope mass balance equation, that allows the calculation of the contribution 252 of two different sources to the dissolved reservoir, each with a distinctive isotopic 253 signature:

$$
\delta^{x} M e(\%)=\left(f_{\text {source } 1} x \delta^{x} M e_{\text {source } 1}\right)+\left(f_{\text {source } 2} x \delta^{x} M e_{\text {source } 2}\right)
$$

257 Where $\delta^{x} \mathrm{Me}$ denotes either $\delta^{56} \mathrm{Fe}$ or $\delta^{66} \mathrm{Zn}$ and $f$ denotes the fraction of the dissolved $\mathrm{Fe}$ 258 or $\mathrm{Zn}$ contributed from each of the two sources assuming $f_{\text {source } 1}$ and $f_{\text {source } 2}$ add up to 1 .

\subsection{Other Oceanographic Parameters}

262 Salinity, dissolved phosphate $\left(\mathrm{PO}_{4}{ }^{3-}\right)$ and dissolved silicate $(\mathrm{Si})$ concentrations were 263 measured for each bottle at the SAFe station on board the IC2 cruise using standard 264 techniques, while density, potential temperature and dissolved oxygen are taken from 265 shipboard CTD data. Dissolved phosphate and silicate were measured on San Pedro 266 samples using standard techniques in the Benitez-Nelson lab at U.S.C. (Koroleff, 1983), 
267 and have an associated uncertainty of $\sim 1 \%\left(\sim 3 \%\right.$ below $\left.1 \mu \mathrm{mol} \mathrm{kg}{ }^{-1}\right)$. Other San Pedro 268 parameters are taken from John et al. (2012).

\subsection{Dissolved Cd* and Zn*}

$272 \mathrm{Cd}^{*}$ and $\mathrm{Zn}^{*}$ are parameters that can be used to show variability in the relationship 273 between $\mathrm{Cd}$ and $\mathrm{PO}_{4}{ }^{3-}$ or $\mathrm{Zn}$ and $\mathrm{Si}$ in the water column (Baars et al., 2014; Janssen et al., 274 2014; Wyatt, et al., 2014). These are useful when investigating in-situ processes that 275 might affect the trace metals but not the macronutrients. In this study we calculate $\mathrm{Cd}^{*}$ 276 and $\mathrm{Zn}^{*}$ following the equations used in Janssen et al. (2014) and Conway and John 277 (2014b; 2015):

$$
C d^{*}=[C d]_{\text {measured }}-\left(\mathrm{Cd} / \mathrm{PO}_{4}^{3-}{ }_{\text {deep }} *\left[\mathrm{PO}_{4}^{3-}\right]_{\text {measured }}\right)
$$

$$
Z n^{*}=[Z n]_{\text {measured }}-\left(Z n / S i_{\text {deep }} *[S i]_{\text {measured }}\right)
$$

285 designed to highlight variability and so are expressed relative to reference ratios. In this 286 study we set $\left(\mathrm{Cd} / \mathrm{PO}_{4}{ }^{3-}\right)_{\text {deep }}(0.317)$ and $\mathrm{Zn} / \mathrm{Si}_{\text {deep }}(0.056)$ to the mean of the measured 287 ratios $\geq 2000 \mathrm{~m}$ at the SAFe station (see Suppl. Data), to represent deep Pacific waters 288 below the influence of low-oxygen $\left(<75 \mu \mathrm{mol} \mathrm{L}^{-1}\right)$ waters. We express uncertainty on $\mathrm{Cd}^{*}$ 289 and $\mathrm{Zn}^{*}$ values (Supp. Information) using standard error propagation of the uncertainty 290 of $\mathrm{Cd}, \mathrm{Zn}, \mathrm{PO}_{4}{ }^{3-}$ and $\mathrm{Si}$ concentration measurements (see Sections 2.2 and 2.3).

\section{Results and Discussion}

294 Water-column concentration and stable isotope ratio profiles for dissolved $\mathrm{Fe}, \mathrm{Zn}$ and $\mathrm{Cd}$ 295 at SAFe are shown in Figs 2-3. Water column concentration and isotope profiles for 296 dissolved Fe, $\mathrm{Zn}$ and $\mathrm{Cd}$ at San Pedro are shown in Fig. 5, with Fe reproduced from John 
297 et al. (2012). We begin by discussing data from SAFe and the processes that control the 298 distribution of each element there, and then go on to discuss the same for $\mathrm{Cd}$ and $\mathrm{Zn}$ at 299 San Pedro.

\section{$301 \quad 3.1 \mathrm{Fe}$ and $\delta^{56} \mathrm{Fe}$ at $\mathrm{SAFe}$}

302

303

\subsubsection{Patterns in dissolved $\mathrm{Fe}$ and $\delta^{56} \mathrm{Fe}$}

305 The dissolved Fe concentration and $\delta^{56} \mathrm{Fe}$ profiles measured from $\mathrm{SAFe}$ are shown in Fig. 306 2a. At SAFe, the water column was characterized by low Fe concentrations in the surface 307 ocean $\left(<0.1 \mathrm{nmol} \mathrm{kg}^{-1} ;<100 \mathrm{~m}\right)$, a Fe maximum at intermediate depths $\left(0.7 \mathrm{nmol} \mathrm{kg}^{-1}\right.$; $308 \quad 1000-1500 \mathrm{~m})$ and lower Fe concentrations within deep Pacific waters $(\sim 0.4-0.5 \mathrm{nmol} \mathrm{kg}$ $\left.309{ }^{1}>2000 \mathrm{~m}\right) . \delta^{56} \mathrm{Fe}$ values throughout the water column at SAFe ranged from -0.6 to $310+0.1 \%$, with isotopically lighter $\delta^{56} \mathrm{Fe}(-0.33$ to $-0.55 \%$ o corresponding to the depths of 311 the oxygen minimum zone $\left(<75 \mu \mathrm{mol} \mathrm{kg}{ }^{-1} ; \sim 550-2000 \mathrm{~m}\right.$; Figs $\left.2-3\right)$. The lightest $\delta^{56} \mathrm{Fe}$ 312 values were observed just above the OMZ, within NPIW at $500 \mathrm{~m}(-0.64 \%)$, and at the

313 dissolved $\mathrm{Fe}$ concentration maximum at $1500 \mathrm{~m}\left(0.7 \mathrm{nmol} \mathrm{kg}{ }^{-1} ;-0.55 \%\right)$, while the

314 heaviest $\delta^{56} \mathrm{Fe}$ were observed close to the surface $(+0.02 \pm 0.24 \%$ ond $+0.07 \pm 0.25 \%$ o $)$

315 where Fe concentrations are low, and in deep waters below $3800 \mathrm{~m}(+0.15 \pm 0.07 \%$ ond $316+0.18 \pm 0.07 \%$; Fig. 2a).

318 The dissolved Fe concentration profile from SAFe in this study (collected May 2009) is 319 very similar to that reported by Wu et al. (2011) for a SAFe profile collected in 2004 320 (grey line, Fig. 2a), suggestive of a relatively stable Fe cycle over this timescale. 321 Measurement of isotopically light $\delta^{56} \mathrm{Fe}$ at $1000 \mathrm{~m}$ in this study $(-0.33 \pm 0.06 \%$ o $)$ is 322 consistent with our previous measurements in SAFe D1 and D2 reference standards, 323 collected from $1000 \mathrm{~m}$ at SAFe in $2004(-0.24 \pm 0.05 \%$ o to $-0.39 \pm 0.12 \%$; Conway et al., 324 2013). Our measured $\delta^{56} \mathrm{Fe}$ values in D1 and D2 standards (Table 3, Conway et al., 2013) 325 were within error of each other, despite D1 suffering from precipitation of up to $~ 30 \%$ 326 during sub-sampling from the un-acidified SAFe $1000 \mathrm{~L}$ tank, presumably due to wall 327 adsorption/precipitation (Johnson et al., 2007). Thus, precipitation of Fe within the tank 
328 proceeded with apparently negligible fractionation of $\mathrm{Fe}$ isotopes. This increases our 329 confidence in the fidelity of $\delta^{56} \mathrm{Fe}$ measurements for similar samples obtained from deep 330 low-oxygen waters that could potentially be compromised by similar processes, albeit on 331 a lesser scale.

333 The vertical structure of dissolved $\mathrm{Fe}$ and $\delta^{56} \mathrm{Fe}$ at $\mathrm{SAFe}$, with higher concentrations of 334 lighter $\mathrm{Fe}$ at 500-2000 m, largely associated with the OMZ, and lower concentrations of 335 heavier $\delta^{56} \mathrm{Fe}$ both above and below this horizon, should be considered in the context of 336 possible vertical and horizontal processes. In the surface ocean, vertical in situ processes 337 that have the potential to influence $\mathrm{Fe}$ and $\delta^{56} \mathrm{Fe}$ include 1) mineral dust deposition and 338 dissolution, 2) biological uptake in surface waters with regeneration at depth, and 3) 339 vertical upward mixing and scavenging/precipitation of Fe from OMZ conditions to 340 higher oxygen waters. In the intermediate and deep ocean, lateral transport of Fe, either 341 within water masses or carried throughout low-oxygen waters within the North Pacific 342 OMZ ( 550-2000 m), may be a strong influence on dissolved $\delta^{56} \mathrm{Fe}$. Below, we discuss 343 the possible effects of these various processes on the distribution of dissolved $\delta^{56} \mathrm{Fe}$ and 344 Fe at SAFe.

\subsubsection{Vertical and in situ processes influencing $\delta^{56} \mathrm{Fe}$ in surface waters}

348 Over the top $\sim 350 \mathrm{~m}$, where dissolved $\mathrm{Fe}$ is $\leq 0.2 \mathrm{nmol} \mathrm{kg}^{-1}, \delta^{56} \mathrm{Fe}$ values are slightly 349 isotopically light or crustal $(-0.2$ to $+0.1 \%)$, and heavier than at intermediate depths $(-0.4$ 350 to $-0.6 \%$ o). There are several possible processes which could cause this pattern. Perhaps 351 the simplest idea would be a contribution of isotopically heavy Fe from atmospheric dust 352 mixing with isotopically light Fe from below, accompanied by little-to-no fractionation 353 during biological uptake/regeneration. If biological uptake/regeneration takes place with

354 negligible $\delta^{56} \mathrm{Fe}$ fractionation, uptake/regeneration will be indistinguishable from vertical 355 mixing. If the net $\delta^{56} \mathrm{Fe}$ signature of mineral dust in the North Pacific is similar to that 356 suggested for the North Atlantic (+0.68\%o; John and Conway, 2014a), a rough mass 357 balance calculation using Eq. 4 would suggest that $\delta^{56} \mathrm{Fe}$ data over the surface $200 \mathrm{~m}$ 
358 could be explained by a 40-50\% contribution from mineral dust and 50-60\% contribution

359 from upwelling of light Fe (-0.64\%o at $500 \mathrm{~m})$.

360

361 Alternatively, it is possible that biological uptake of light Fe drives the surface ocean to

362 heavier values, and then potentially regenerates deeper in the water column (Radic et al.,

363 2011; Ellwood et al., 2015). However, there are few direct culture or open-ocean studies

364 so far, and evidence for such a strong fractionation of $\delta^{56} \mathrm{Fe}$ by biological uptake is

365 mixed, suggesting a complex interplay of biological processes may interact to influence

$366 \delta^{56} \mathrm{Fe}$. To illustrate this, a recent study of bloom development in the sub-tropical Pacific

367 suggested that smaller phytoplankton may take up light Fe, driving the dissolved pool to

368 heavier values, while diatom uptake of Fe showed no $\delta^{56} \mathrm{Fe}$ fractionation (Ellwood et al., 369 2015). That study also suggested that light $\delta^{56} \mathrm{Fe}$ in surface waters $(0-125 \mathrm{~m})$ prior to

370 bloom development could be caused by bacterial or photochemical reduction of $\mathrm{Fe}$

371 (Ellwood et al., 2015). Our recent study from the North Atlantic showed no clear

372 evidence for the biological uptake of light $\mathrm{Fe}$, but instead demonstrated a decrease in

$373 \delta^{56} \mathrm{Fe}$ near the fluorescence maximum which is consistent with a preferential biological

374 removal of heavy $\mathrm{Fe}$ isotopes or release of light Fe by biological processes (Conway and 375 John, 2014a). Consequently, while biological activity may affect $\delta^{56} \mathrm{Fe}$ in surface waters, 376 both the magnitude and direction of these processes on $\delta^{56} \mathrm{Fe}$ at $\mathrm{SAFe}$ remain unclear.

377 Regardless, the effects of biological processes on $\delta^{56} \mathrm{Fe}$ are likely to be limited to depths 378 above $500 \mathrm{~m}$, where most other nutrient elements (e.g. N, P, Cd) are regenerated.

379

380 Another factor to consider is that oxidation/precipitation reactions and particle 381 adsorption/desorption might fractionate Fe isotopes. At SAFe, oxidation and precipitation 382 of $\mathrm{Fe}$ as waters are vertically mixed from OMZ depths ( 550-2000 $\mathrm{m})$ to higher oxygen 383 conditions might lead to redox-associated fractionation (Skulan et al., 2002; Johnson et 384 al., 2002; John et al., 2012). However, there are few field studies available to constrain 385 the effect of these processes on $\delta^{56} \mathrm{Fe}$ under oceanic conditions. Changes in $\delta^{56} \mathrm{Fe}$ 386 associated with oxidation/precipitation have been observed in the Black Sea, where $\delta^{56} \mathrm{Fe}$ 387 changed from $-0.4 \%$ to $+0.3 \%$ across the anoxic-oxic boundary (Staubwasser et al., 388 2013). However, this was associated with an order of magnitude change in $\mathrm{Fe}$ 


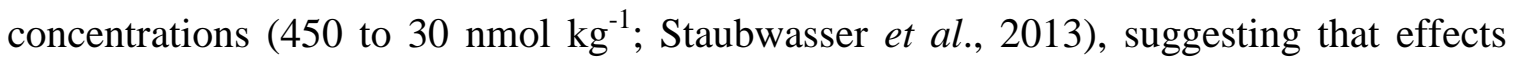

390 might be much more muted in open-ocean settings where $\mathrm{Fe}$ is present at lower 391 concentrations and changes in Fe across OMZ boundaries are much smaller (this study; 392 Conway and John, 2014a). Similarly, precipitation of Fe(III) within the water column of

393 the San Pedro basin was modeled with a $\Delta \delta^{56} \mathrm{Fe}_{\text {particle-dissolved }}$ of -0.8 (John et al., 2012);

394 however, at San Pedro, high Fe concentrations and related rapid precipitation of dissolved

$395 \mathrm{Fe}(\mathrm{III})$ might lead to a different Fe isotope effect than in open-ocean settings. Indeed, at

$396 \mathrm{SAFe}$ the pattern in $\delta^{56} \mathrm{Fe}$ and Fe provides little evidence for dramatic precipitation at the

397 top of the OMZ (Fig. 2a). Dissolved Fe only drops from 0.64 to $0.47 \mathrm{nmol} \mathrm{kg}^{-1}$ between

398750 to $500 \mathrm{~m}$ depth, despite oxygen rising over this interval from 19 to $100 \mu \mathrm{mol} \mathrm{kg}{ }^{-1}$.

399 Additionally, $\delta^{56} \mathrm{Fe}$ become lighter through this range (-0.4 to $-0.6 \%$ ), rather than

400 heavier. Taken together, this pattern suggests it is unlikely that the heavier $\delta^{56} \mathrm{Fe}$ at depths

401 shallower than $500 \mathrm{~m}$ are the result of in situ precipitation. Relatively small changes to

402 dissolved $\mathrm{Fe}$ and $\delta^{56} \mathrm{Fe}$ associated with increasing oxygen at SAFe might be because light

403 dissolved $\mathrm{Fe}$ within the $\mathrm{OMZ}$ is already largely present as $\mathrm{Fe}(\mathrm{III})$, limiting fractionation

404 between dissolved $\mathrm{Fe}(\mathrm{II})-\mathrm{Fe}(\mathrm{III})$, which can cause large changes in $\delta^{56} \mathrm{Fe}$ (Johnson et al.,

405 2002). Although we have no speciation data, this idea would be consistent with other

406 field studies which suggest that isotopically light Fe above sediments is present as Fe(III)

407 but retains the light $\delta^{56} \mathrm{Fe}$ signature of reduced sediment Fe(II) (Conway and John, 2014a;

408 John et al., 2012; Sedwick et al., 2015).

410 While the in situ effects of precipitation and particle adsorption/desorption on $\delta^{56} \mathrm{Fe}$ 411 remain unclear and a full understanding will require future detailed experiments, we note 412 that apparent negligible fractionation due to adsorption/precipitation in the SAFe tank 413 also lends support to the idea that precipitation of $\mathrm{Fe}$ (III) within the open-ocean water 414 column may not greatly change $\delta^{56} \mathrm{Fe}$ source signatures. This would be consistent with 415 the broad scale patterns of $\delta^{56} \mathrm{Fe}$ in the North Atlantic and evidence from locations such 416 as San Pedro (Conway and John, 2014a; John et al., 2012), which suggest that dissolved $417 \quad \delta^{56} \mathrm{Fe}$ retains source signatures during mixing and transport, making it possible to use $418 \delta^{56} \mathrm{Fe}$ as a tracer of Fe sources through the ocean. 
422 Over the last two decades, a key goal of ocean biogeochemical modeling studies has been

423 to understand how Fe is supplied to the surface ocean where it can be assimilated as a

424 nutrient by phytoplankton. Initially, models focused on the dominance of Fe supplied by

425 aeolian dust to the oceans, largely not considering other sources of Fe (e.g. Archer and

426 Johnson, 2000; Moore et al., 2001; Aumont et al., 2003; Parekh et al., 2004). As field

427 data and modeling studies have advanced, shelf sediments have been subsequently

428 considered as an important source of Fe (e.g. Elrod et al., 2004; Jeandel et al., 2011),

429 with newer models accordingly incorporating a sediment component (e.g. Moore et al.,

430 2004; Moore and Braucher, 2008; Tagliabue et al., 2009). Most recently, the importance

431 of hydrothermal sources of Fe to the ocean has been a focus for research, with long

432 distance transport documented, perhaps due to stabilization with organic molecules

433 (Boyle et al., 2005; Boyle and Jenkins, 2008; Fitzsimmons et al., 2014; Toner et al.,

434 2009; Tagliabue et al., 2010; Wu et al., 2011; Saito et al., 2013). Thus, hydrothermal Fe

435 may be a much more important source than previously considered, especially in the

436 Southern Ocean and South Pacific (Tagliabue et al., 2009), with a recent study suggesting

437 that hydrothermal Fe from the East Pacific Rise travels as far west as New Zealand

438 ( $6000 \mathrm{~km}$; Fitzsimmons et al., 2014). The importance of hydrothermal supply is

439 accordingly considered by the latest ocean biogeochemical models (Tagliabue et al.,

440 2010; Tagliabue et al., 2014), and the aims of recent $\delta^{56} \mathrm{Fe}$ and modeling studies have

441 been to constrain the relative contributions from multiple $\mathrm{Fe}$ sources to the oceans

442 (Conway and John, 2014a; Tagliabue et al., 2014).

444 In the Pacific, where dust deposition is relatively low (Jickells et al., 2005), non-dust 445 sources such as sediments or hydrothermal venting may be more dominant than 446 traditionally considered. $\delta^{56} \mathrm{Fe}$ provides the opportunity to inform such hypotheses about 447 the sources of Fe to the ocean, though they rely on an assumption that source $\delta^{56} \mathrm{Fe}$ is not 448 greatly modified during subsequent transport and reaction. While both the specific 449 conditions under which source $\delta^{56} \mathrm{Fe}$ may be modified during transit and different source 450 end-members are not yet fully constrained, $\delta^{56} \mathrm{Fe}$ does seem to be a tracer for $\mathrm{Fe}$ sources 
451 over great distances under typical open ocean conditions (Conway and John, 2014a).

452 Thus, $\delta^{56} \mathrm{Fe}$ data from $\mathrm{SAFe}$ provides us with the means to begin to investigate the 453 sources of $\mathrm{Fe}$ to this region.

455 Although $\delta^{56} \mathrm{Fe}$ data from the open North Pacific is very limited, with only three 456 published seawater studies from marginal environments (Radic et al., 2011; John et al., 457 2012; Labatut et al., 2014), it can offer some insights into the sources of dissolved Fe. 458 Indeed, the most striking observation about the $\delta^{56} \mathrm{Fe}$ data at $\mathrm{SAFe}$ is the absence of 459 isotopically heavy Fe throughout the entire water column, in contrast to our recently 460 published $\delta^{56} \mathrm{Fe}$ section for the North Atlantic Ocean where $\delta^{56} \mathrm{Fe}$ away from 461 hydrothermal and sedimentary sources was typically $+0.4 \%$ o to $+0.8 \%$ o (Conway and 462 John, 2014a). There, we attributed the isotopically heavy Fe values to Fe released from 463 atmospheric dust, reflecting fractionation during dissolution, perhaps associated with 464 organic ligands (Conway and John, 2014a). The fact that $\delta^{56} \mathrm{Fe}$ values $>+0.1 \%$ are not 465 observed at SAFe, where dust deposition is much lower than in the subtropical North 466 Atlantic ( $<0.5$ vs. $0.5-10 \mathrm{~g} \mathrm{~m}^{-2} \mathrm{yr}^{-2}$; Jickells et al., 2005), combined with the observation 467 that the heaviest $\delta^{56} \mathrm{Fe}$ values are observed nearest the surfce, is consistent with this 468 hypothesis. Similarly a recent observation of $\delta^{56} \mathrm{Fe}$ of $+0.3 \%$ in Equatorial Pacific bulk 469 aerosols (Labatut et al., 2014) provides evidence for an isotopically heavy aerosol source. 470 Thus, data from SAFe are supportive of our previous attribution of heavy Atlantic $\delta^{56} \mathrm{Fe}$ 471 to dust, and are also consistent with an evolving picture that an atmospheric supply of Fe 472 is much less important in the North Pacific than in the North Atlantic.

474 At SAFe, instead of a dominant atmospheric source, we suggest that the light $\delta^{56} \mathrm{Fe}$ and 475 high $\mathrm{Fe}$ concentrations at depths of $\sim 500-2000 \mathrm{~m}$ are indicative of lateral supply of 476 isotopically light $\mathrm{Fe}$. Two possible sources for this isotopically light $\mathrm{Fe}$ are reduced 477 margin sediment sources and hydrothermal venting. The heavier Fe in surface waters 478 would then be attributed to either biological removal of light Fe or input of a heavier Fe 479 source such as mineral dust. Reductive sedimentary Fe sources on the nearby North 480 American continental margin are isotopically light (as light as -3.4\%o; Homoky et al., 481 2009; Severmann et al., 2010; John et al., 2012), and while the net $\delta^{56} \mathrm{Fe}$ signatures of 
482 hydrothermal source signals are currently poorly constrained, any Pacific hydrothermal

483 source responsible for light $\delta^{56} \mathrm{Fe}$ would by definition also be light. $\delta^{56} \mathrm{Fe}$ measurements

484 alone thus cannot distinguish between isotopically light sedimentary and hydrothermal

$485 \mathrm{Fe}$, and so we must also consider the broad scale pattern of other parameters such as Fe

486 concentration and hydrothermal tracers such as $\delta^{3} \mathrm{He}$ from other studies.

488 Recently, hydrothermal $\mathrm{Fe}$ and $\delta^{56} \mathrm{Fe}$ signatures have been shown to be traceable over 489 1000-2000 km in the Atlantic (Saito et al., 2013; Conway and John, 2014a). If Fe is 490 stabilized in the form of nano-particulate sulfides from sulfide-rich vent fluids which are 491 common in Pacific hydrothermal systems, it might travel even greater distances in the 492 Pacific (Yucel et al., 2011). This idea is supported by observational studies which found 493 hydrothermally-derived Fe up to $6000 \mathrm{~km}$ away from vent sites (Fitzsimmons et al., 494 2014; Wu et al., 2011). It is therefore feasible that hydrothermal Fe could be transported 495 from either Loihi or Juan de Fuca, which are both 2000 km away, to SAFe. However, 496 hydrothermal activity and the lateral transport of dissolved Fe can be traced using 497 elevated $\delta^{3} \mathrm{He}$ (e.g. Wu et al., 2011; Saito et al., 2013;). Although widespread 498 hydrothermal $\delta^{3} \mathrm{He}$ anomalies are observed within the intermediate depth North Pacific 499 (1000-2000 m; Figs. 1, 2b.), at SAFe both the dissolved Fe maximum at $1500 \mathrm{~m}$ and 500 isotopically light $\mathrm{Fe}$ at 500-1500 m correspond poorly to the $\delta^{3} \mathrm{He}$ maximum (1800-2200;

501 Fig. 2b). This suggests that a hydrothermal source is unlikely to be responsible for the 502 light Fe observed at SAFe from 500-2000 m.

504 The second possibility is lateral transport of Fe from a light sedimentary margin source, 505 through the low-oxygen horizon at $\sim 550-2000 \mathrm{~m}$. Release of Fe(II) under low-oxygen 506 conditions results in very isotopically light $\delta^{56} \mathrm{Fe}(\sim-3 \%)$ both in pore-waters on the 507 Californian Margin and also within the water column of the Californian low-oxygen San 508 Pedro and Santa Barbara basins (Homoky et al., 2009; Severmann et al., 2010; John et 509 al., 2012). The data of John et al. (2012) showed that the light $\delta^{56} \mathrm{Fe}$ signature from 510 sediments was widespread within the water column of these restricted basins, allowing 511 for this light $\delta^{56} \mathrm{Fe}$ signature to be upwelled into the Californian Current and/or 512 transported into the open ocean Pacific (e.g. Biller and Bruland, 2013). Consistent with 
513 the idea of reduced margin Fe being transported out into the open ocean Pacific, previous

514 work also showed a large dissolved Fe plume (0.8-1.2 $\left.\mathrm{nmol} \mathrm{kg}^{-1}\right)$ present within the

515 North Pacific OMZ, extending from the Californian margin all the way to the SAFe

516 station (Johnson et al., 1997). That pattern, with Fe concentrations decreasing away from

517 the margin, but with concentrations of $\sim 0.8 \mathrm{nmol} \mathrm{kg}^{-1}$ at $\sim 1000-1600 \mathrm{~m}$ reaching SAFe

518 (Johnson et al., 1997) is consistent with the attribution of isotopically light Fe at SAFe to

519 a sedimentary source. Taken together, the pattern of different datasets suggests that

520 Californian Margin sediments are a likely source for the light Fe within the OMZ at

521 SAFe.

522

523 3.1.4 Variability in $\delta^{56} \mathrm{Fe}$ between 500-2000 $\mathrm{m}$ depth

524

525 Set against the general idea of a reductive sedimentary source of Fe to OMZ waters at $526 \sim 550-2000 \mathrm{~m}$, we do observe variability in $\delta^{56} \mathrm{Fe}$ between $500-2500 \mathrm{~m}$. The minimum in $527 \delta^{56} \mathrm{Fe}$ at $1500 \mathrm{~m}(-0.55 \%)$ is consistent with the idea of a plume of sedimentary $\mathrm{Fe}$ 528 extending from the Californian Margin with maximum extent at depths of $\sim 1000-1600 \mathrm{~m}$

529 (Johnson et al., 1997). The presence of slightly heavier $\delta^{56} \mathrm{Fe}$ values at depths of 750-

$5301000 \mathrm{~m}(-0.3$ to $-0.4 \%$ o), where Fe concentrations are slightly lower, is also consistent

531 with the idea of a lessening influence of sediment Fe at shallower depths within the OMZ

532 as oxygen concentration rises. At $500 \mathrm{~m}$, where oxygen has risen to $100 \mu \mathrm{mol} \mathrm{kg}{ }^{-1}$, we

533 might expect an even smaller contribution from the Californian Margin and even heavier

$534 \delta^{56} \mathrm{Fe}$. Instead, we observe the lightest $\delta^{56} \mathrm{Fe}$ anywhere in the water column at SAFe at $535500 \mathrm{~m}\left(-0.64 \%\right.$ ) . This could be the result of fractionation of $\delta^{56} \mathrm{Fe}$ towards the top of the

536 OMZ, although that would be expected to shift values to heavier $\delta^{56} \mathrm{Fe}$ (Section 3.1.2), or 537 might point to a second source of light Fe. This source might also be from the Californian 538 Margin or could be related to NPIW, which is present at $500 \mathrm{~m}$ depths at SAFe.

540 The light $\delta^{56} \mathrm{Fe}$ signature observed associated with NPIW at SAFe could originate in the 541 northern North Pacific source regions for NPIW, as appears to be the case for $\mathrm{Zn} *$ and $542 \mathrm{Cd}^{*}$ (see Sections 3.2-3.3). Although $\delta^{56} \mathrm{Fe}$ data has not been previously reported for 543 NPIW, this low-salinity water mass corresponds to high Fe concentrations at $\sim 500 \mathrm{~m}$ in 
544 the North Western Pacific (1-1.5 $\mathrm{nmol} \mathrm{kg}^{-1}$; Nishioka et al., 2007). These high $\mathrm{Fe}$ 545 concentrations were attributed to ventilation of high-Fe intermediate depth waters in the 546 surface sub-polar regions where NPIW is formed in the Okhotsk Sea and the Oyashio 547 Region, and lateral transport within NPIW (Talley, 1993; Nishioka et al., 2007). Given 548 that these high Fe concentrations are likely sourced from the Asian margin and carried in 549 low-oxygen waters (Nishioka et al., 2007), this Fe might carry a light $\delta^{56} \mathrm{Fe}$ signature 550 from reducing sediments as observed in the North Atlantic OMZ (Conway and John, 551 2014a). If NPIW does carry a pre-formed $\delta^{56} \mathrm{Fe}$ signal, this would be remarkable because 552 it would suggest that a distal Asian shelf or sub-polar source contribues Fe source to the 553 surface ocean in the subtropical North East Pacific. It would also add weight to the idea 554 that non-aeolian sources and light $\delta^{56} \mathrm{Fe}$ signatures can be transported over long distances

$555(\sim 6000 \mathrm{~km})$, despite the dynamic nature of the Fe cycle. In the North Pacific, the relative 556 absence of isotopically heavy Fe sources such as dust could facilitate the transport of 557 light $\delta^{56} \mathrm{Fe}$ signatures over even greater distances than in the Atlantic.

559 Whichever source is responsible for the isotopically lighter $\delta^{56} \mathrm{Fe}$ at 500 and $1500 \mathrm{~m}$, the 560 heavier $\delta^{56} \mathrm{Fe}$ values at $750-1000 \mathrm{~m}$ probably reflect mixing of $\mathrm{Fe}$ sources with a pre561 formed $\delta^{56} \mathrm{Fe}$ signature carried with AAIW (600-1300 m) from the South Pacific. $\delta^{56} \mathrm{Fe}$ 562 data in AAIW from $\sim 20^{\circ} \mathrm{S}$ showed this water mass to be $-0.1 \%$ (Fitzsimmons et al., 563 2013), which is heavier than the water column at SAFe. The range of $\delta^{56} \mathrm{Fe}$ values 564 observed between 750-1000 m could therefore reflect mixing of light Fe from NPIW ($5650.6 \%$ ) with AAIW since these two water masses are mixed in this depth interval (Talley 566 et al., 2011), and/or mixing of background Fe from AAIW with Fe advected from the

567 Californian margin at depths of $\sim 800-1600 \mathrm{~m}$. Higher spatial resolution $\delta^{56} \mathrm{Fe}$ data would 568 be necessary to distinguish these possibilities. 3.1.5 Fe sources below $2000 \mathrm{~m}$ and water column synthesis

571

572 Below $2000 \mathrm{~m}, \delta^{56} \mathrm{Fe}$ returns to heavier values, near -0.1\%o in PDW/UDCDW at 2000$5733000 \mathrm{~m}$ and $+0.15 \%$ o to $+0.18 \%$ in LCDW below $3000 \mathrm{~m}$ (Fig. 2a). This increase in $\delta^{56} \mathrm{Fe}$ 574 values with depth corresponds to declining $\mathrm{Fe}$ concentrations, reflecting both the 
575 lessening influence of horizontally transported sedimentary or hydrothermal $\mathrm{Fe}$, and the 576 influence of scavenging on Fe concentrations in older water. Indeed, LCDW are some of 577 the oldest waters in the world, and the heavier $\delta^{56} \mathrm{Fe}$ values $(+0.2 \% \circ)$ here are close to 578 crustal (+0.09\%; Beard et al., 2003), suggestive of Fe sourced from 'non-reductive' 579 release from sediments or in apparent equilibrium with crustal $\delta^{56} \mathrm{Fe}$ values ( 0 to $+0.3 \%$; 580 Radic et al., 2011; Homoky et al., 2013; Conway and John, 2014a; Labatut et al., 2014).

582 In evaluating the overall sources of $\mathrm{Fe}$ to the water-column at $\mathrm{SAFe}$, therefore, we infer 583 that Fe from reductive sediments is most important at intermediate depths of 500-2000 m, 584 probably due to lateral transport of Fe from the Californian Margin through the Oxygen 585 Minimum Zone, with possible addition from NPIW. Vertical upwelling of light Fe from 586 the OMZ horizon, together with mineral dust deposition at the surface, can explain 587 heavier $\delta^{56} \mathrm{Fe}$ in surface waters above $200 \mathrm{~m}$, although here $\delta^{56} \mathrm{Fe}$ signatures may be 588 complicated by a range of other processes. Below the OMZ, Fe in deep waters (>4000 m)

589 is likely sourced from contact with oxic sediments, while it is not yet clear from the 590 available data whether lighter than crustal $\delta^{56} \mathrm{Fe}$ values in PDW/UCDW (1500-4000 m)

591 reflect a reduced sedimentary or very distal hydrothermal signal. Overall, $\delta^{56} \mathrm{Fe}$ data from

592 SAFe point to sedimentary margins being the dominant Fe sources in this region of the 593 North Pacific, in agreement with both recent modeling efforts and $\delta^{56} \mathrm{Fe}$ measurements 594 from ferromanganese crusts which suggest that deep sedimentary or hydrothermal $\mathrm{Fe}$ 595 sources may have dominated the deep Pacific Fe reservoir over the last $\sim 80$ million years 596 (Chu et al., 2006; Horner et al., 2014; Tagliabue et al., 2014).

\section{$598 \quad 3.2 \mathrm{Cd}$ and $\delta^{114} \mathrm{Cd}$ at SAFe}

600 The dissolved Cd concentration profile at SAFe (Fig. 3a) is typical for Cd in the North 601 Pacific (e.g. Bruland, 1980). Dissolved Cd is characterised by low concentrations $(<20$ $602 \mathrm{pmol} \mathrm{kg}^{-1}$ ) at the surface, increasing rapidly with depth to a subsurface maximum of $603 \sim 1040 \mathrm{pmol} \mathrm{kg}^{-1}$ at $1000 \mathrm{~m}$ (associated with AAIW). Below $1000 \mathrm{~m}, \mathrm{Cd}$ concentrations 604 are slightly lower in deep waters dominated by UCDW/PDW and LCDW (860-920 pmol $605 \mathrm{~kg}^{-1}$ ). At SAFe $\delta^{114} \mathrm{Cd}$ is remarkably homogenous at depths of $500 \mathrm{~m}$ and below (Fig. 3a; 
606 mean $0.32 \pm 0.04 \%$; 2SD $\mathrm{n}=8) . \quad \delta{ }^{114} \mathrm{Cd}$ from $1000 \mathrm{~m}$ in this study from 2009 $607(+0.31 \pm 0.04 \%, 2 \sigma)$ are consistent with our previous measurements of $\delta{ }^{114} \mathrm{Cd}$ in SAFe D1 608 and D2 standards from $1000 \mathrm{~m}$ that were collected in 2004 (mean $+0.26 \pm 0.02 \%$ o, 2SD, $609 \mathrm{n}=5$; Conway et al., 2013). Above $500 \mathrm{~m}, \delta^{114} \mathrm{Cd}$ increases from $+0.30 \pm 0.04 \%$ o to $610+0.78 \pm 0.08 \%$ at $200 \mathrm{~m}$, as Cd concentrations decline from 800 to $138 \mathrm{pmol} \mathrm{kg}^{-1}$. In the

611 surface ocean above $200 \mathrm{~m}, \delta^{114} \mathrm{Cd}$ increases to even heavier values $(+3 \%$ ) as $\mathrm{Cd}$

612 concentrations become very depleted due to biological uptake within the euphotic zone.

613 Here, biological incorporation of light $\mathrm{Cd}$ into phytoplankton leaves the residual 614 dissolved $\mathrm{Cd}$ pool isotopically heavy, with the very heavy $\delta^{114} \mathrm{Cd}$ surface values 615 consistent with previously reported values of +3 to $+5 \%$ for similar low concentration 616 surface waters in the Pacific and Atlantic (Ripperger et al., 2007; Conway and John, 617 2015).

619 The overall pattern in $\mathrm{Cd}$ and $\delta^{114} \mathrm{Cd}$ reflects what is known about dissolved $\mathrm{Cd}$ and $620 \delta^{114} \mathrm{Cd}$ in the oceans, namely that both are controlled by large-scale water mass 621 circulation and influenced by biological activity in surface waters (e.g Ripperger et al., 622 2006; Abouchami et al., 2014). A range of studies from different oceans now show $623 \delta^{114} \mathrm{Cd}$ to be fairly homogenous $(+0.2$ to $+0.3 \%$ ) in deep waters with $\mathrm{Cd}$ concentrations 624 of 0.4-1 $\mathrm{nmol} \mathrm{kg}^{-1}$ from the Pacific, Southern and Atlantic Oceans and the South China 625 Sea (Ripperger et al., 2007; Boyle et al., 2012; Xue et al., 2012; Yang et al., 2012; 626 Conway et al., 2013; Abouchami et al., 2014). We represent this deep-water $\delta^{114} \mathrm{Cd}$ value 627 as a purple dashed line in Fig. 3a $(\sim+0.3 \%)$. Biological uptake and incomplete 628 regeneration, either in situ or via advection of preformed water-mass signals are 629 responsible for higher $\delta^{114} \mathrm{Cd}$ values in surface waters $(<500 \mathrm{~m})$ or through the 630 intermediate depth Atlantic (Abouchami et al., 2014; Conway and John, 2015). The 631 vertical gradients in $\mathrm{Cd}$ and $\delta^{114} \mathrm{Cd}$ observed at SAFe above $500 \mathrm{~m}$ are mostly likely the 632 result of a combination of biological uptake of light $\mathrm{Cd}$ in the euphotic zone, together 633 with deeper regeneration and vertical upward mixing of deep waters. It is also possible 634 horizontal advection of nutrient-depleted surface water masses could also contribute to 635 heavier $\delta^{114} \mathrm{Cd}$ above $500 \mathrm{~m}$. 
637 Consistent with the now-widely known global $\mathrm{Cd} / \mathrm{PO}_{4}{ }^{3-}$ relationship, dissolved $\mathrm{Cd}$ and $638 \mathrm{PO}_{4}{ }^{3-}$ profiles at $\mathrm{SAFe}$ are very similar (Fig. 3a). Indeed, the North East Pacific was the 639 focus of some of the first studies that demonstrated the strong global correlation between 640 these two elements (Boyle et al., 1976; Bruland et al., 1978a; Bruland, 1980), with the 641 broad scale distribution of both elements being broadly controlled by the same physical 642 and biological factors. Despite the broad similarity between the two nutrients, processes 643 that add or remove phosphate or cadmium from the oceans can cause small variations in 644 the $\mathrm{Cd} / \mathrm{PO}_{4}{ }^{3-}$ and $\mathrm{Cd}^{*}$. Variability in the degree of uptake and regeneration of $\mathrm{Cd}$ and $645 \mathrm{PO}_{4}{ }^{3-}$ in surface waters that set the pre-formed $\mathrm{Cd} / \mathrm{PO}_{4}{ }^{3-}$ of water masses, and local 646 removal of $\mathrm{Cd}$ can both influence $\mathrm{Cd} / \mathrm{PO}_{4}{ }^{3-}$ and $\mathrm{Cd}^{*}$ (Baars et al., 2014; Janssen et al., 647 2014).

649 Recent data from Line $\mathrm{P}$, in the sub-arctic Pacific showed a negative $\mathrm{Cd}^{*}(-0.1)$ 650 associated with the top of low-oxygen waters, attributed to the in situ removal of $\mathrm{Cd}$ from 651 the water column as CdS (Janssen et al., 2014). At SAFe, a similar excursion to negative $652 \mathrm{Cd}^{*}$ is seen associated with the top of the $\mathrm{OMZ}$, with $\mathrm{Cd}^{*}$ values reaching -0.12 at $750 \mathrm{~m}$ 653 where dissolved oxygen is $\sim 10 \mu \mathrm{mol} \mathrm{kg}{ }^{-1}$. This is supportive of the idea of water column 654 removal of $\mathrm{Cd}$ associated with the onset of low-oxygen conditions, as previously 655 hypothesized in the North Pacific and North Atlantic (Janssen et al., 2014; Conway and 656 John, 2015). In fact, at $750 \mathrm{~m}$, the difference in $\mathrm{Cd}_{\text {and }} \mathrm{PO}_{4}{ }^{3-}$ can also be clearly observed 657 in the shape of the two profiles (Fig. 3a). It has been hypothesized that dissolved $\mathrm{Cd}$ is 658 removed within low-oxygen, but not anoxic, open ocean waters as isotopically light $\mathrm{Cd}$ 659 sulfides (Janssen et al., 2014), and recently it was shown that in the North Atlantic this 660 leaves the residual dissolved $\delta^{114} \mathrm{Cd}$ isotopically heavy (John and Conway, 2014). At $661 \mathrm{SAFe}$, however, there is no evidence of any change in dissolved $\delta^{114} \mathrm{Cd}$ associated with 662 the $\mathrm{Cd}^{*}$ signal. This may be because the isotope fractionation associated with sulfide 663 formation is small, or that the relative removal of $\mathrm{Cd}$ in the North Pacific is less than in 664 the North Atlantic.

666 The observed $\mathrm{Cd}^{*}$ excursions of around -0.1 at $500-1000 \mathrm{~m}$ at SAFe and at Line $\mathrm{P}$ in the 667 North Pacific are smaller than $\mathrm{Cd}^{*}$ minima (-0.24 to -0.25) reported from the top (90 m 
668 depth; $45 \mu \mathrm{mol} \mathrm{kg}{ }^{-1}$ oxygen) of the Mauritanian OMZ in the North Atlantic (Conway and 669 John, 2015; Janssen et al., 2014), but are broadly comparable with the -0.05 to $-0.15 \mathrm{Cd}^{*}$ 670 signal seen throughout North Atlantic low oxygen waters (Conway and John, 2015). 671 Given that the North Pacific OMZ is characterized by a pronounced low oxygen horizon 672 ( 550-2000 m; Fig. 2b) with dissolved oxygen concentrations as low as $10 \mu \mathrm{mol} \mathrm{kg}^{-1}$, it 673 is perhaps surprising that a similarly large change in both $\delta^{114} \mathrm{Cd}$ and $\mathrm{Cd}^{*}$ is not observed 674 in the Pacific. However, there are several factors which may be responsible for this 675 difference. First, $\mathrm{Cd}$ is supplied to the intermediate depth North Atlantic by Antarctic 676 Intermediate Water (AAIW), which is slightly depleted in Cd relative to $\mathrm{PO}_{4}{ }^{3-}$ compared 677 deep North Atlantic reference waters (AAIW $\mathrm{Cd}^{*}$ of -0.02 to -0.04 ; Conway and John, 678 2015), while the top of the OMZ at SAFe is influenced by NPIW with a Cd* of -0.01 to $679+0.01$. Second, the degree to which metal sulfides are removed may depend not only on 680 dissolved oxygen concentrations, but also the availability of organic particle micro681 environments in which metal sulfides may form (Janssen et al., 2014; Janssen and Cullen, 682 2015). Such environments may be more abundant in the Eastern North Atlantic where 683 there is intense biological activity related to the Mauritanian Upwelling region. 684 Additionally, organic particle concentrations are likely to be higher at the top of the 685 Mauritanian OMZ at $100 \mathrm{~m}$ depth, compared to $750 \mathrm{~m}$ depth in the North Pacific, due to 686 regeneration of organic matter with depth. Together, these factors may provide more 687 particulate micro-environments for metal sulfide formation in the North Atlantic. This in 688 turn may facilitate a more dramatic effect on the dissolved $\mathrm{Cd}$ reservoir at the top of the 689 shallow Mauritanian OMZ compared to a more subtle effect throughout the deeper North 690 Pacific OMZ. However, despite the more subtle Cd* signals in the North Pacific, the $6910.12 \mathrm{Cd}^{*}$ minimum at $\mathrm{SAFe}$ still corresponds to a dissolved Cd concentration (917 pmol $\left.692 \mathrm{~kg}^{-1}\right)$ which is $120 \mathrm{pmol} \mathrm{kg}^{-1}$ less than would be predicted $\left(1040 \mathrm{pmol} \mathrm{kg}^{-1}\right)$ from a Cd* of 6930 based on deep water $\mathrm{Cd} / \mathrm{PO}_{4}{ }^{3}$. This suggests that $\mathrm{CdS}$ removal does have the potential 694 to be an important process for the distribution and cycling of $\mathrm{Cd}$ in this region of the 695 ocean, consistent with recent studies (Conway and John, 2015; Janssen et al., 2014).

697 In surface waters above $500 \mathrm{~m}, \mathrm{Cd}^{*}$ is $\sim 0$ at the surface $(25 \mathrm{~m})$, perhaps reflecting near698 quantitative uptake of both $\mathrm{Cd}$ and $\mathrm{P}$, or simply water-mass differences. Deeper in the 
699 water column, within high-oxygen surface waters, $\mathrm{Cd}^{*}$ declines to -0.10 at $200 \mathrm{~m}$ and 700 then returns to $\sim 0$ at $350 \mathrm{~m}$ It is not yet clear what is causing this shape in surface $\mathrm{Cd}^{*}$, 701 although a similar feature is also observed at Line P (Janssen et al., 2014). The pattern 702 could point to the differential regeneration of $\mathrm{Cd}$ and $\mathrm{PO}_{4}{ }^{3-}$ in surface waters, or 703 advection of a signal from another region of the ocean. Just above the OMZ, at $500 \mathrm{~m}$, a 704 profile maximum in $\mathrm{Cd}^{*}(+0.01)$ is observed associated with the presence of NPIW. This 705 water-mass is slightly enriched in $\mathrm{Cd}$ with a $\mathrm{Cd} / \mathrm{PO}_{4}{ }^{3-}$ of 0.314 compared to the deep

706 Pacific (0.317), probably reflecting transport of a pre-formed $\mathrm{Cd} / \mathrm{PO}_{4}{ }^{3-}$ signature from the 707 source regions of NPIW in the Oktoshk Sea (0.37; Abe, 2002).

\subsection{Zn and $\delta^{66} \mathrm{Zn}$ at SAFe}

711 Dissolved $\mathrm{Zn}$ at SAFe and in the North Pacific has a similar profile to dissolved silicate

712 (Fig. 3b, this study; Bruland et al., 1978b), with low concentrations in surface waters due

713 to biological uptake and a gradual increase with depth, reaching a maximum of $\sim 9 \mathrm{nmol}$

$714 \mathrm{~kg}^{-1}$ within PDW/UCDW (3000 m). Both Zn and Si reach their concentration maximum 715 at a much deeper depth than Cd or P. Set against this broad pattern, Zn* data indicates 716 that NPIW at $500 \mathrm{~m}$, and AAIW mixed with NPIW at $750 \mathrm{~m}$ are both characterized by 717 higher $\mathrm{Zn} / \mathrm{Si}$ than the deep ocean. As we described above, NPIW is characterized by high $718 \mathrm{Cd} / \mathrm{PO}_{4}{ }^{3-}$ and light $\delta^{56} \mathrm{Fe}$, which in the latter case we hypothesize could be carried from 719 reductive sediments in the NPIW source regions in the Sea of Okhotsk. It is possible that 720 the higher Zn* observed within NPIW at SAFe is a transported source signal with $\mathrm{Zn}$ 721 entrained into NPIW close to the Asian margin, and carried with the water mass through 722 the intermediate North Pacific. This idea is consistent with several recent studies which 723 showed high Zn concentrations relative to Si within NPIW at Line P (Janssen and Cullen, 724 2015) and high concentrations of $\mathrm{Zn}$ in the sub-artic source regions for NPIW (Sea of 725 Okhotsk and Sea of Japan; Kim et al., 2015). It is certainly feasible that the Zn* signal in 726 NPIW could be a preformed water-mass signature, since preformed $\mathrm{Zn}$ * appears to be a 727 conservative tracer within the oceans (e.g. Wyatt, et al., 2014). Data from several 728 GEOTRACES sections have already shown that elevated $\mathrm{Zn} *$ signals can be transported 729 great distances. For example, $\mathrm{Zn} *$ within Mediterranean Outflow water travels from $35^{\circ} \mathrm{N}$ 
730 at least as far as $17^{\circ} \mathrm{N}$, and $\mathrm{Zn} *$ within Upper Labrador Sea Water appears to travel even 731 further (Conway and John, 2014b). Antarctic Zn* water mass signals are also transported 732 northward into the South Atlantic (Wyatt et al., 2014). We recently showed that margin 733 sediments are sources of dissolved Zn (Conway and John, 2014b), an observation that is

734 repeated for the Californian Margin in this study. Similarly, the slight source of $\mathrm{Zn}$ to 735 NPIW could be sediments on the Asian margin, or a riverine or anthropogenic source of 736 Zn from East Asia. Additionally, Kim et al. (2015) recently suggested that elevated Zn 737 within NPIW source regions could be caused by atmospheric dust input to surface waters. 738

739 In the deep ocean at SAFe, below $500 \mathrm{~m}, \delta^{66} \mathrm{Zn}$ is quite homogenous ( +0.45 to $+0.56 \%$ ), 740 close to the mean $\delta^{66} \mathrm{Zn}$ of $+0.50 \pm 0.14 \%$ 。 $\mathrm{SD}$ (2SE of $0.01, \mathrm{n}=223$ ) of the global oceans $741 \geq 1000 \mathrm{~m}$, calculated from data obtained so far (means of $0.53 \pm 0.14 \%$, $2 \mathrm{SD} \mathrm{n}=21$, in 742 Zhao et al. (2014), and 0.50+0.13\%o, 2SD n=202, in Conway and John (2014b)). Above $743500 \mathrm{~m}$, in contrast to $\delta^{114} \mathrm{Cd}, \delta^{66} \mathrm{Zn}$ gradually decreases upward from $+0.5 \%$ o to values as 744 light as $-0.05 \pm 0.09 \%$ at $100 \mathrm{~m}$ and $-0.15 \pm 0.06 \%$ at $25 \mathrm{~m}$. This pattern of increasing $745 \delta^{114} \mathrm{Cd}$ and decreasing $\delta^{66} \mathrm{Zn}$ towards the surface at $\mathrm{SAFe}$ is similar to recent water746 column data from the North Atlantic, where these signals were attributed primarily to 747 biological uptake (Cd), and scavenging ( $\mathrm{Zn}$ ), respectively (John and Conway, 2014). In

748 the latter-case, the suggestion of a role for scavenging was based on the oceanographic 749 patterns of $\mathrm{Zn}$ and $\delta^{66} \mathrm{Zn}$, culture experiments demonstrating adsorption of heavy $\mathrm{Zn}$ to 750 degrading phytoplankton and simple 1-dimensional modeling studies (John and Conway, 751 2014; Conway and John, 2014b). More recently, adsorption of isotopically heavy $\mathrm{Zn}$ to 752 organic material has also been demonstrated in incubation experiments with biofilms 753 (Coutard et al., 2014).

754

755 The pattern in $\delta^{66} \mathrm{Zn}$ observed at SAFE is also similar to the two previous published 756 studies of $\delta^{66} \mathrm{Zn}$ from the North Pacific, which showed light values $(-0.1$ to $+0.2 \%$ o over 757 the top $200-400 \mathrm{~m}$ and then an increase to deep ocean values of $+0.5 \%$ o below this 758 (Bermin et al., 2006; John, 2007). Culture studies show that phytoplankton preferentially 759 incorporate lighter $\mathrm{Zn}$, a fact typically invoked to explain heavy $\delta^{66} \mathrm{Zn}$ values in very 760 surface waters in other oceans (e.g. up to $+0.9 \%$; John et al., 2007a; Conway and John, 
761 2014b). Indeed, in the North Atlantic, a decrease in $\delta^{66} \mathrm{Zn}$ from the deep ocean towards

762 the surface is often accompanied by an increase to heavier $\delta^{66} \mathrm{Zn}$ values at the very 763 surface. At SAFe, however, we do not have data for the very surface, so it is not clear if $764 \delta^{66} \mathrm{Zn}$ moves to heavier values, although our recent $\delta^{66} \mathrm{Zn}$ measurement in the SAFe S1

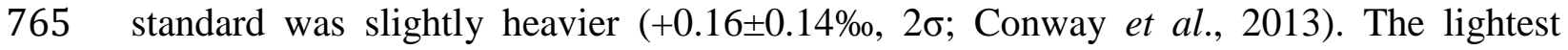
$766 \delta^{66} \mathrm{Zn}$ value $(25 \mathrm{~m})$ is coincident with elevated $\mathrm{Zn}$ concentration $\left(0.7 \mathrm{nmol} \mathrm{kg}{ }^{-1}\right)$, and it is 767 not clear if this represents very shallow recycling of biogenic light $\mathrm{Zn}$ as has been 768 suggested for the North Pacific (Vance et al., 2012), cells bursting on filters during 769 collection, or contamination (although the latter would be expected to be +0.1 to $+0.3 \%$; 770 John et al., 2007b).

772 Despite the current global dataset for seawater $\delta^{66} \mathrm{Zn}$ demonstrating the near773 homogeneity of the deep ocean (>500 m) for $\delta^{66} \mathrm{Zn}$ (Conway and John, 2014b; Zhao et 774 al., 2014; this study), there does appear to be small variability, on the order of $0.1-0.2 \%$. 775 This variability is thus close to, but outside of, the limits of precision of deep ocean $\delta^{66} \mathrm{Zn}$ 776 data ( 0.02-0.08\%o; Conway and John, 2014b; Zhao et al., 2014). At SAFe, $\delta^{66} \mathrm{Zn}$ values

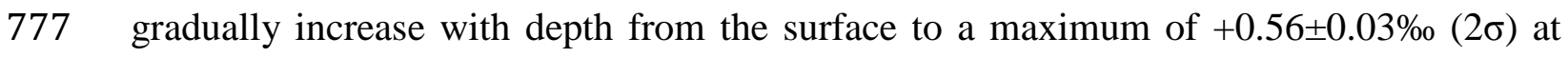
$77875-1000 \mathrm{~m}$, and then decline to $+0.52 \%$ o between $1500-3000 \mathrm{~m}$ and to $+0.46 \pm 0.02 \%$ o $(2 \sigma)$ 779 within deeper waters. While this $0.1 \%$ offset in $\delta^{66} \mathrm{Zn}$ at SAFe is close to the combined $7802 \sigma$ error on the data $(0.04-0.06 \%$ o), the pattern hints at a profile shape that can also be 781 observed in data from other oceans, where the shift to heavier values at mid-depths is 782 larger. (Fig. 4; Conway and John, 2014b; Zhao et al., 2014). For example, we recently 783 documented a mid-depth $\delta^{66} \mathrm{Zn}$ maximum in the intermediate North Atlantic Ocean, with 784 heavy $\delta^{66} \mathrm{Zn}$ (up to $+0.7 \%$ ) at intermediate depths of $750-2000 \mathrm{~m}$ at 7 stations in the 785 eastern North Atlantic (Fig. 4.; Fig. 8 of Conway and John, 2014b). With the recent 786 publication of full water-column profiles of $\delta^{66} \mathrm{Zn}$ from the South Atlantic, heavy $\delta^{66} \mathrm{Zn}$ 787 (+0.6 to $+0.7 \%$ o) was also observed at intermediate depths of $\sim 1000-3000$ at two stations 788 in the South Atlantic and at 3000-4000 $\mathrm{m}$ in one station in the South Atlantic (Zhao et al., 789 2014). In the one example where the mid-depth maximum is observed at deeper depths 790 within Southern Ocean Station PS71-104-2 (Zhao et al., 2014), the heavier $\delta^{66} \mathrm{Zn}$ values 
791 are present partially within LCDW, which is subducted from intermediate depths further 792 south.

794 While these excursions to heavier $\delta^{66} \mathrm{Zn}$ at intermediate depths in the North Atlantic,

795 North Pacific and Southern Ocean are small in magnitude ( 0.1 to $0.2 \%$ ), the values fall 796 outside $2 \mathrm{SE}$ (and in some cases $2 \mathrm{SD}$ ) of the calculated deep ocean mean $\delta^{66} \mathrm{Zn}$ value. 797 Additionally, the pattern is reproduced in different areas of the ocean by two independent 798 laboratories, suggesting that may be a real feature of Zn biogeochemistry that is occurring 799 at intermediate depths within the ocean. This tells us several things. Firstly, this pattern in $800 \delta^{66} \mathrm{Zn}$ suggests that $\mathrm{Zn}$ is not behaving as a simple nutrient-type element, i.e. controlled 801 just by water-mass circulation and biological uptake/regeneration. In contrast to $\delta^{66} \mathrm{Zn}$, 802 both $\delta^{114} \mathrm{Cd}$ and $\delta^{30} \mathrm{Si}$ show simpler isotope profiles, with heavier values in surface ocean 803 due to biological uptake, and large-scale distributions controlled by mixing of water 804 masses with different 'biological' preformed signatures (Abouchami et al., 2014; 805 Conway and John, 2015; de Souza et al., 2012a; de Souza et al., 2012b). Secondly, 806 although some rivers have heavy dissolved $\delta^{66} \mathrm{Zn}$ signatures, the overall $\delta^{66} \mathrm{Zn}$ signature 807 of external $\mathrm{Zn}$ inputs to the oceans is thought to be isotopically lighter than seawater 808 (Little et al., 2014). This means that mid-depth excursions to heavier $\delta^{66} \mathrm{Zn}$ values must 809 be the result of fractionation associated with internal cycling such as the regeneration of a 810 heavy adsorbed $\mathrm{Zn}$ phase or the removal of a light $\mathrm{Zn}$ phase such as $\mathrm{Zn}$ sulfides from the 811 dissolved Zn reservoir (Conway and John, 2014b; John and Conway, 2014; Zhao et al., 812 2014).

814 In the South Atlantic profiles described by Zhao et al. (2014), in contrast to the North 815 Atlantic, dissolved oxygen is always $>150 \mu \mathrm{mol} \mathrm{kg} \mathrm{kg}^{-1}$, and so $\mathrm{ZnS}$ removal is not 816 considered likely. In other areas of the oceans, where low-oxygen waters are present, the 817 situation may not be as simple. A $\mathrm{ZnS}$ removal process has been recently proposed to 818 explain a Zn deficit within low-oxygen waters within the North Pacific OMZ at Line P 819 (Janssen and Cullen, 2015), analogous to that proposed for Cd (Janssen et al., 2014). This $820 \mathrm{Zn}$ deficit was observed at Line P as a subtle decoupling of $\mathrm{Zn}$ and Si at depths of 400$8211000 \mathrm{~m}$, with Zn concentrations decreasing, remaining stable, or increasing less than Si 
822 with depth through this horizon (Janssen and Cullen, 2015). At all 5 of the Line P

823 stations, although especially closest to the coast, a 'bite' appeared to be missing from the $824 \mathrm{Zn}$ concentration depth profiles (Janssen and Cullen, 2015). At the SAFe station, by 825 comparison, $\mathrm{Zn}$ and Si profiles look more similar (Fig. 3b). As a result, $\mathrm{Zn}$ * at SAFe does 826 not provide any clear evidence of $\mathrm{ZnS}$ removal, in contrast to $\mathrm{Cd}$ at SAFe (Fig. 3a; 827 Section 3.2) or both Cd and Zn at Line P (Janssen and Cullen, 2015; Janssen et al., 2014). 828 However, both the full $\mathrm{Zn}^{*}$ profile and $\mathrm{Zn} *$ just above the OMZ (500 m depth) at SAFe 829 are dominated by the positive $\mathrm{Zn}^{*}$ in NPIW (+1). It is possible this NPIW $\mathrm{Zn}^{*}$ signal 830 could be obscuring negative $\mathrm{Zn} *$ excursions at 750-1000 m associated with $\mathrm{ZnS}$ removal, 831 which are observed at deeper depths (-0.1 to $-0.3 ; 1500-2000 \mathrm{~m})$. Additionally, the $\mathrm{Zn}$ 832 deficit at Line $\mathrm{P}$ appeared to diminish along the transect away from the coast, suggesting 833 that removal may depend on the greater availability of particle micro-environments near 834 the coast (Janssen and Cullen, 2015). If this is the case, a $\mathrm{Zn} *$ signal at SAFe might be 835 expected to be much more subtle than at Line $\mathrm{P}$, and could perhaps be overprinted by 836 local processes such as scavenging and regeneration or mixing with other water masses.

838 In terms of $\delta^{66} \mathrm{Zn}$ evidence, it is worth noting that the heaviest $\delta^{66} \mathrm{Zn}$ values at SAFe 839 correspond to the most negative $\mathrm{Cd}^{*}$ values, where it might be expected the strongest 840 effect of $\mathrm{ZnS}$ removal on $\delta^{66} \mathrm{Zn}$ would be observed (Fig. 3). This pattern is also consistent 841 with the idea that $\mathrm{ZnS}$ removal would be expected to drive the resultant dissolved $\delta^{66} \mathrm{Zn}$ 842 to heavier values, as sulfide precipitation is expected to preferentially incorporate light $843 \mathrm{Zn}$ (Archer et al., 2004). Thus, ZnS removal remains a possible candidate for explaining 844 the pattern in $\delta^{66} \mathrm{Zn}$ at SAFe, alongside the idea of adsorption of heavy $\mathrm{Zn}$ within the 845 subsurface ocean together with regeneration of this pool at intermediate depths (Conway 846 and John, 2014b). Both processes are also possible candidates for the mid-depth $\delta^{66} \mathrm{Zn}$ 847 maxima in the Eastern North Atlantic, although this is located below the Mauritanian 848 OMZ (Conway and John, 2014b). Thus, at present we cannot conclusively say whether $849 \mathrm{ZnS}$ removal or regeneration of an adsorbed phase, or a combination of the two, might be 850 responsible for the observed mid-depth maximum observed in seawater $\delta^{66} \mathrm{Zn}$ profiles 851 (Conway and John, 2014b; this study; Fig. 4). However, the fact that heavier mid-depth $852 \delta^{66} \mathrm{Zn}$ maxima have also been observed in the Southern Ocean (Zhao et al., 2014), where 
853 oxygen is not low, would seem to at least provide supporting evidence for the hypothesis 854 that adsorption and regeneration of $\mathrm{Zn}$ plays a global role in the deeper regeneration of 855 Zn compared to other nutrients (John and Conway, 2014).

857 Lastly, we note that the lighter $\delta^{66} \mathrm{Zn}$ values of deepest waters (within LCDW) at SAFe 858 are slightly lighter $(+0.46 \%$ ) , similar to the Western North Atlantic (close to $+0.45 \%$; 859 Conway and John, 2014b). Zn* values are also slightly higher (Fig. 3b). This $\delta^{66} \mathrm{Zn}$ value 860 is subtly lighter than the deep ocean average published to date $(+0.5 \%$; Conway and 861 John, 2014b; Zhao et al., 2014). Although this may be due to uncertainty on 862 measurements, it may also be because whole ocean mean calculations are biased by 863 present coverage that favours intermediate depths. We suggest more coverage of the 864 world's oceans for $\delta^{66} \mathrm{Zn}$ are therefore necessary to establish an accurate deep ocean 865 average $\delta^{66} \mathrm{Zn}$ value (and its spatial variability), that will be important for future attempts 866 to understand or model the overall ocean mass balance of $\mathrm{Zn}$.

\subsection{Cd, $\delta^{114} \mathrm{Cd}, \mathrm{Zn}$ and $\delta^{66} \mathrm{Zn}$ at San Pedro}

869

870 The vertical profiles of both $\mathrm{Zn}$ and $\mathrm{Cd}$ concentrations and stable isotope ratios in the San 871 Pedro basin (Fig. 5b-c) can be interpreted in the context of water-mass mixing together 872 with local processes such as biological activity and sediment interactions. With the 873 exception of samples from 50 and $100 \mathrm{~m}$ depths, the profiles may be largely discussed in 874 terms of vertical and local horizontal processes that fractionate $\delta^{114} \mathrm{Cd}$ and $\delta^{66} \mathrm{Zn}$ from 875 deep ocean signatures of $+0.5 \%$ o $\left(\delta^{66} \mathrm{Zn}\right)$ and $+0.3 \%$ o $\left(\delta^{114} \mathrm{Cd}\right)$. The 50 and $100 \mathrm{~m}$ samples 876 (grey bar, Fig. 5a-c) are strongly influenced by the southward flow of the low salinity 877 California Current system waters (CC; 33-33.4 p.s.u; King and Barbeau, 2011). At these 878 southerly latitudes the low-salinity California Current has a subsurface core at depths of $87950-100 \mathrm{~m}$, can travel close to the coast $(<10 \mathrm{~km})$ and recirculates at these depths through 880 the South California Bight (Lynn and Simpson, 1987; Reid, 1958). The California 881 Current system provides variable upwelling of nutrients and trace metals to the surface 882 mixed layer along the Californian margin, dependent on local upwelling and mesoscale 883 eddies (King and Barbeau, 2011; Biller and Bruland, 2014). Thus, the California Current 
884 is likely to sporadically carry high concentrations of nutrients and trace-metals to the San

885 Pedro water-column, overprinting local processes. We therefore discuss these two parts 886 of the profiles separately; first, we discuss the vertical profiles without the samples from $88750-100 \mathrm{~m}$, and then consider the two samples from 50-100 m separately.

889 At San Pedro, Cd concentrations decrease from a maximum of $1040 \mathrm{pmol} \mathrm{kg}^{-1}$ at $900 \mathrm{~m}$ 890 in the deep basin, to much lower concentrations in surface waters ( $40 \mathrm{pmol} \mathrm{kg}^{-1}$ at $\left.35 \mathrm{~m}\right)$, 891 very similar to the concentrations observed at the open-ocean SAFe station. As at SAFe, $892 \delta^{114} \mathrm{Cd}$ is close to $+0.3 \%$ o below $500 \mathrm{~m}$, with an increase in $\delta^{114} \mathrm{Cd}$ towards heavier values 893 in surface waters $(+0.85 \%$ at $35 \mathrm{~m})$, indicative of the influence of biological uptake and 894 regeneration of $\mathrm{Cd}$ in shallower waters. With the exception of the $35 \mathrm{~m}$ sample, dissolved $895 \mathrm{Cd}$ and $\mathrm{PO}_{4}{ }^{3-}$ profiles show similarity throughout the water column, with $\mathrm{Cd}^{*}$ values 896 ranging from +0.00 to +0.07 . It is not clear what causes the slight fluctuations in $\mathrm{Cd}^{*}$, but 897 the smaller values at $35 \mathrm{~m}$ and $800 \mathrm{~m}$ are associated with fluctuations in $\mathrm{PO}_{4}{ }^{3-}$, perhaps 898 pointing to an external source of phosphate from sediments at these depths. Despite the 899 low-oxygen concentrations $\left(<75 \mu \mathrm{mol} \mathrm{L}^{-1}\right)$ present below $200 \mathrm{~m}$ of the San Pedro water 900 column, and the evidence for CdS precipitation at open-ocean North Pacific sites (this 901 study; Janssen et al., 2014), there is less clear $\mathrm{Cd}^{*}$ or $\delta^{114} \mathrm{Cd}$ evidence for in situ $\mathrm{CdS}$ 902 precipitation within the water column at San Pedro, when compared to SAFe or Line P. 903 As discussed in Section 3.2, in both the North Atlantic and North East Pacific, a negative $904 \mathrm{Cd}^{*}$ signal is seen largely associated with the top of low-oxygen waters (this study; 905 Janssen et al., 2014; Conway and John, 2015), suggesting that another factor such as the 906 presence of high concentrations of biological particles is facilitating $\mathrm{Cd}$ removal as $\mathrm{CdS}$ 907 in micro-environments (Conway and John, 2015; Janssen and Cullen, 2015). It could be 908 that there are not sufficient quantities of these particles at intermediate depths (150-200 $909 \mathrm{~m})$ in the San Pedro basin, or that a $\mathrm{Cd}^{*}$ signal is largely obscured by the northward 910 movement of the Californian Undercurrent at these depths (Talley et al., 2011). However, 911 it should be noted that a small minimum in $\mathrm{Cd}^{*}(+0.00)$ and a pronounced minimum in $912 \mathrm{Zn} *(-0.3)$ are both observed at $\sim 150 \mathrm{~m}$ where dissolved oxygen drops below $100 \mu \mathrm{mol}$

$913 \mathrm{~L}^{-1}$. These provide possible evidence for small water-column loss of both $\mathrm{Cd}$ and $\mathrm{Zn}$ due 914 to sulfide formation as oxygen concentrations decline. 
916 The distribution of dissolved $\mathrm{Zn}$ in the San Pedro basin, in contrast to Cd, cannot simply

917 be interpreted in the context of biological uptake and regeneration. Zn concentrations at

$918 \sim 800 \mathrm{~m}$ are similar to that observed at SAFe (6.7 vs $6.62 \mathrm{nmol} \mathrm{\textrm {kg } ^ { - 1 }}$ ), and decrease

919 towards the surface. However, $\delta^{66} \mathrm{Zn}$ values are always lighter than 'oceanographic'

920 ( +0.5\%o, dashed blue line), with the heaviest values at $800 \mathrm{~m}(+0.43 \%)$, and decreasing

921 towards the surface $(+0.11 \%$ at $35 \mathrm{~m})$. This could reflect the influence of adsorption of $\mathrm{Zn}$

922 to organic matter, has been suggested for the North Atlantic and at SAFe (this study; John

923 and Conway, 2014). The muted excursion to lighter $\delta^{66} \mathrm{Zn}$ values towards the surface in

924 San Pedro compared to the SAFe station (+0.11 vs. $-0.15 \%$ ) could also be explained by

925 lower organic particle availability. Between $150-500 \mathrm{~m}, \mathrm{Zn} *$ and $\delta^{66} \mathrm{Zn}$ profiles have a

926 similar shape, supporting the idea that heavy $\mathrm{Zn}$ is being removed from the water column.

927 Below this, the opposite shape of the $\mathrm{Zn}$ and $\delta^{66} \mathrm{Zn}$ profiles suggests that addition of

928 isotopically light $\mathrm{Zn}$ is causing the pattern in both $\mathrm{Zn}^{*}$ and $\delta^{66} \mathrm{Zn}$. As has been

929 documented for Fe in the San Pedro (John et al., 2012), this source is likely to be margin

930 sediments. In fact with the exception of $150 \mathrm{~m}, \mathrm{Zn}^{*}$ values are elevated throughout the

931 top $800 \mathrm{~m}(+0.3$ to +1$)$, indicative of a 'non-oceanographic' (i.e. not with a $\mathrm{Zn} / \mathrm{Si}$ ratio of

9320.056 and a $\delta^{66} \mathrm{Zn}$ of $+0.5 \%$ ) source of $\mathrm{Zn}$ throughout the water column at San Pedro.

933

934 Both adsorption/removal of heavy $\mathrm{Zn}$ and addition of sedimentary $\mathrm{Zn}$ are likely to be 935 occurring to different degrees throughout the full water column at San Pedro, 936 complicating efforts to use $\delta^{66} \mathrm{Zn}$ alone to fully constrain processes. However, within the 937 silled basin below $800 \mathrm{~m}$, dissolved $\mathrm{Zn}$ concentrations increase dramatically from $\sim 7$ $938 \mathrm{nmol} \mathrm{kg}{ }^{-1}$ at $800 \mathrm{~m}$ to $11 \mathrm{nmol} \mathrm{kg}^{-1}$ at $900 \mathrm{~m}$, coupled with a decrease in $\delta^{66} \mathrm{Zn}$ to $+0.15 \%$ o 939 and a large excursion in $\mathrm{Zn}^{*}($ to +5$)$. The absence of enhanced dissolved silicate 940 concentrations at these depths indicates that this $\mathrm{Zn}$ is 'non-oceanographic', i.e. not

941 sourced from deeper nutrient-rich waters, and is consistent with a flux of isotopically 942 light $\mathrm{Zn}$ from sediments. This release of $\mathrm{Zn}$ is similar to that described for dissolved $\mathrm{Fe}$ in 943 the San Pedro, with vertical transport of Fe from reduced sedimentary porewater in

944 benthic sediments thought to dominate the water column below the basin sill depth (John

945 et al., 2012). If we simply assume that the increase in $\mathrm{Zn}$ between 800-895 m (+4.2 nmol 
$\left.946 \mathrm{~kg}^{-1}\right)$ and the decline in $\delta^{66} \mathrm{Zn}(+0.44$ to $+0.15 \%$ ) is caused by addition of sedimentary $\mathrm{Zn}$ 947 we can use these differences in $\mathrm{Zn}$ and $\delta^{66} \mathrm{Zn}$ and a simple two component isotope mass

948 balance equation (Eq. 4) to approximate the $\delta^{66} \mathrm{Zn}$ signature of the sedimentary $\mathrm{Zn}$. This

949 calculation generates a sedimentary $\delta^{66} \mathrm{Zn}$ signature of $-0.3 \%$, which is lighter than

950 known values of crustal, anthropogenic and bulk sediment $\mathrm{Zn}$ under various redox

951 conditions (+0.1 to $+0.3 \%$; Archer et al., 2004; Chapman et al., 2006; John et al., 2007b;

952 Little et al., 2014; Maréchal et al., 2000).

954 The form and mechanism of release of this sedimentary $\mathrm{Zn}$ is still unknown, as a pore-

955 water or sedimentary release of $\mathrm{Zn}$ has not yet been characterized in situ within

956 sediments. However, the light $\delta^{66} \mathrm{Zn}$ signatures inferred for San Pedro sediment release

957 are similar to $\delta^{66} \mathrm{Zn}$ inferred for both oxic and reductive margins in the North Atlantic

$958\left(\delta^{66} \mathrm{Zn}\right.$ of -0.5 to $-0.8 \%$; Conway and John, 2014b). There, we suggested one explanation

959 for such light $\delta^{66} \mathrm{Zn}$ values could be the release of biogenic $\mathrm{Zn}$ from sediments. This 960 could also be the source of light $\delta^{66} \mathrm{Zn}$ release at San Pedro. Alternatively dissolution of

961 Zn sulfides, which would be expected to be isotopically light (Archer et al., 2004), could

962 be a source of $\mathrm{Zn}$ to the water column. These $\mathrm{Zn}$ sulfides could have formed in anoxic

963 sediments and then perhaps be redissolved or remobilized as colloids $(<0.2 \mu \mathrm{m})$ as the

964 deep basin is periodically flushed by higher oxygen water (John et al., 2012).

966 Future sedimentary studies will be required to investigate the mechanism by which $\mathrm{Zn}$ is 967 released from ocean floor sediments to the water column, as well as for characterizing the 968 chemical form of this 'dissolved Zn'. Nevertheless, despite a lack of understanding of the 969 mechanism by which this $\mathrm{Zn}$ might be released, it is clear from water-column data that 970 margin sediments can be large local sources of $\mathrm{Zn}$ under both low and high oxygen 971 conditions (this study; Conway and John, 2014b). It is also clear that sediments in these

972 environments are sources of both $\mathrm{Zn}$ and $\mathrm{Fe}$, but not of dissolved $\mathrm{Cd}$. While there is 973 insufficient spatial data to constrain how widespread Zn release might be on the Southern 974 Californian Margin, or whether dissolved $\mathrm{Zn}$ released from sediments is transported out 975 into the open-ocean, distal transport is plausible. Other studies provide some insight into 976 how margin sediments might influence phytoplankton in the open ocean, showing 
977 elevated dissolved $\mathrm{Fe}$ in the surface mixed layer and water-column off California, 978 attributed to a benthic Fe supply (e.g. Bruland et al., 2001). Similarly, recent work from 979 central California demonstrate a supply of trace metals $(\mathrm{Mn}, \mathrm{Fe}, \mathrm{Co}, \mathrm{Cu})$ from benthic 980 sediments to the CC system (Biller and Bruland, 2013), although they found no

981 substantial addition of dissolved $\mathrm{Zn}$ or $\mathrm{Cd}$. Perhaps consistent with that study, the very 982 elevated $\mathrm{Zn}^{*}$ values at San Pedro are confined to the deep silled basin. However, $\mathrm{Zn}^{*}$

983 values of +0.3 can be observed throughout the water column, including within the 984 Californian Current (see below), suggesting a small but observable contribution of $\mathrm{Zn}$ 985 from sediments.

987 For the two samples at 50-100 m depth, we observe elevated dissolved concentration of $988 \mathrm{Zn}\left(4-5 \mathrm{nmol} \mathrm{kg}{ }^{-1}\right), \mathrm{Cd}\left(900 \mathrm{pmol} \mathrm{kg}^{-1}\right)$, Si $\left(70-80 \mathrm{nmol} \mathrm{L}^{-1}\right)$ and $\mathrm{PO}_{4}{ }^{3-}\left(2.8 \mathrm{nmol} \mathrm{L}^{-1}\right)$ 989 associated with low salinity (33.2-33.4 p.s.u). This low-temperature, low-salinity ( $<33.4$ 990 p.s.u.) water at shallow depths is characteristic of the southward flowing California 991 Current along the Californian coast (Lynn and Simpson, 1987; King and Barbeau, 2011) 992 which recirculates through the South California Bight at these depths (Reid, 1958). The 993 elevated nutrient concentrations, together with deeper-water signatures of both $\delta^{66} \mathrm{Zn}$ $994(+0.4 \%)$ and $\delta^{114} \mathrm{Cd}(+0.4 \%)$, are suggestive of upwelling of deeper water to the $50-100$ 995 m layer, associated with Ekman and sporadic eddy-driven upwelling on the Californian 996 Margin (Talley et al., 2011). Dissolved Fe concentrations at 50-200 m are also elevated 997 (4 $\left.\mathrm{nmol} \mathrm{L}^{-1}\right)$, and isotopically light $\left(\delta^{56} \mathrm{Fe}\right.$ near $-1.2 \%$; John et al., 2012), also suggestive 998 of upwelling of deep water with a sedimentary Fe source.

1000 An alternative explanation for the two errant data points could be that bottles were 1001 tripped at the wrong depth, and we can use data from the three elements to consider that 1002 possibility. Of the three isotope systems, $\delta^{114} \mathrm{Cd}$ is simply affected by biological uptake 1003 and regeneration, leading to a vertical monotonic increase towards the surface, and so is 1004 most diagnostic for establishing the depth of upwelled water. A dissolved $\mathrm{Cd}$ 1005 concentration of $900 \mathrm{pmol} \mathrm{kg}^{-1}$ and a $\delta^{114} \mathrm{Cd}$ of $+0.4 \%$ are are similar to $\sim 350 \mathrm{~m}$ depth 1006 waters at the SAFe station. However, the $\delta^{66} \mathrm{Zn}$ and $\delta^{56} \mathrm{Fe}$ signals, as well as $\mathrm{Fe}$ and $\mathrm{Zn}$ 1007 concentrations would indicate much deeper depths, around $\sim 750 \mathrm{~m}$. The data are 
1008 therefore inconsistent with the samples being from a deeper depth in the San Pedro water 1009 column, and so we can discount the idea that bottles were mis-tripped. Of course, this 1010 consideration also means that the elevated concentrations are unlikely to be the result of 1011 in-situ upwelling within the San Pedro basin itself. Instead, the signals may arise from 1012 upwelled deep water from further north that has been laterally advected into the San 1013 Pedro basin with the California Current. One possibility for the source of the metals at 1014 shallower depths is the Santa Barbara Basin (560 m deep), which is located just to the

1015 North West of the San Pedro (Fig. 1a), and where much higher concentrations of Fe (4-6

$\left.1016 \mathrm{nmol} \mathrm{L}{ }^{-1}\right)$ and low $\delta^{56} \mathrm{Fe}$ signatures $(\sim-1 \%$ o have been documented at depths of 300-400 1017 m (John et al., 2012). Sporadic eddy-driven upwelling from depths of several hundred 1018 meters is in fact typical of the California current system, with the southern region (32$101936^{\circ} \mathrm{N}$ ) showing strongest upwelling through the summer and as late as September, when 1020 these samples were collected (Talley et al., 2011).

1022 Data from San Pedro adds weight to the idea that Fe from reductive sediments may be 1023 upwelled and carried laterally within the California current systems along the margin, 1024 providing a source of $\mathrm{Fe}$ to phytoplankton outside these basins, as has been suggested 1025 throughout the CC system (King and Barbeau, 2011; Biller and Bruland, 2013; Biller and 1026 Bruland, 2014). Additionally, elevated $\mathrm{Zn} *$ in the two samples from the $\mathrm{CC}$ suggests that 1027 a sedimentary $\mathrm{Zn}$ source is also present at locations further North along the Californian 1028 margin and more widespread than just the San Pedro basin, though such a signal was not 1029 observed in data from Central California (Biller and Bruland, 2013). Low oxygen 1030 sediments along the margin are therefore potentially a source of not just $\mathrm{Fe}$ to the 1031 Southern California Current system (e.g. Johnson et al., 1999), but also Zn as well. 1032 Globally, sediments under low-oxygen waters may be an important sources of $\mathrm{Zn}$ in other 1033 regions with similar hydrography to the Californian Current System, or where anoxic 1034 basins are periodically flushed with higher-oxygen waters.

1035

1036

\section{Concluding remarks and basin-wide synthesis}

1037 
1038 We have presented two multiple-isotope $\left(\delta^{56} \mathrm{Fe}, \delta^{66} \mathrm{Zn}\right.$ and $\left.\delta^{114} \mathrm{Cd}\right)$ profiles for the North 1039 Pacific, one from the SAFe station in the open-ocean subtropical North East Pacific and 1040 another from the San Pedro marginal basin on the Californian margin. These data 1041 represent the first full-water column profiles for $\delta^{66} \mathrm{Zn}$ and $\delta^{56} \mathrm{Fe}$ profile from the open-

1042 ocean North Pacific and the first observations of dissolved $\delta^{66} \mathrm{Zn}$ and $\delta^{114} \mathrm{Cd}$ in a low1043 oxygen marginal basin.

1045 At the basin scale, these data have allowed us to provide insights into the differing cycles 1046 of Fe, $\mathrm{Zn}$ and $\mathrm{Cd}$ in the North Pacific Ocean. At SAFe, data suggests that the Fe budget 1047 over the top $2000 \mathrm{~m}$ is dominated by isotopically light dissolved $\delta^{56} \mathrm{Fe}$, which we suggest 1048 points to lateral transport and mixing of sedimentary Fe from reduced Californian margin 1049 sediments through the pronounced North Pacific Oxygen Minimum Zone at 550-2000 $1050 \mathrm{~m}$ depth. This idea is consistent with studies showing a plume of higher dissolved Fe 1051 concentration extending $2000 \mathrm{~km}$ from the Californian Margin to SAFe, and the very 1052 isotopically light signature of pore-waters and water-column $\delta^{56} \mathrm{Fe}$ along the North 1053 American margin including the San Pedro basin (Johnson et al., 1997; Severmann et al., 1054 2010; John et al., 2012). While the possible influence of hydrothermal Fe at intermediate 1055 depths at $\mathrm{SAFe}$ is not apparent from $\delta^{56} \mathrm{Fe}$ data, we cannot discount the possibility that 1056 hydrothermal $\mathrm{Fe}$ is present at $\mathrm{SAFe}$ with a $\delta^{56} \mathrm{Fe}$ signature similar to other $\mathrm{Fe}$ sources 1057 which are present at the same depths. Heavier values $(\sim+0.2 \%$ o) in deep waters (below $1058<4000 \mathrm{~m})$ are consistent with a non-reductive sedimentary source of Fe. In general, the 1059 much lighter $\delta^{56} \mathrm{Fe}$ observed in the North Pacific, compared to the North Atlantic, 1060 supports our previous attribution of isotopically heavy Fe to dust in the North Atlantic, 1061 and is consistent with the emerging consensus that aeolian dust deposition is not the only 1062 important source of Fe to the global ocean. Our data also provide support for the idea that $1063 \delta^{56} \mathrm{Fe}$ source signatures may be maintained over great distances and can therefore be used 1064 to provide a useful tool for tracing sources of Fe through the ocean.

1066 At $500 \mathrm{~m}$ depth, where oxygen is slightly higher than within the OMZ $\left(100 \mu \mathrm{mol} \mathrm{kg}{ }^{-1}\right)$, 1067 North Pacific Intermediate Water carries a very light $\delta^{56} \mathrm{Fe}$ signature $(-0.6 \%)$, which 1068 could point to an additional reduced sedimentary input in NPIW source regions. $\mathrm{Cd}^{*}$ and 
$1069 \mathrm{Zn}^{*}$ are also distinctive in this water mass, highlighting the potential importance of 1070 processes in NPIW source regions for the distribution of these trace metals at shallow 1071 depths $(\leq 500 \mathrm{~m})$ in the North Pacific. Indeed, at the broad scale, consistent with current 1072 knowledge, data from both SAFe and San Pedro suggests that the distribution of both Cd 1073 and $\mathrm{Zn}$ in the North Pacific are most strongly influenced by water-mass circulation, with 1074 biological uptake/regeneration in surface waters $<500 \mathrm{~m} . \delta^{114} \mathrm{Cd}$ at both locations is 1075 characterized by a deep water signature $(\sim+0.3 \%$ o below $500 \mathrm{~m}$, and fractionation 1076 towards heavier values in surface waters, attributed to biological uptake of light $\mathrm{Cd}$ into 1077 phytoplankton. In addition to this overall pattern, however, low-oxygen waters may play 1078 a small additional role in the regional distribution of $\mathrm{Cd}$. Negative $\mathrm{Cd}^{*}$ values within the 1079 Pacific OMZ at SAFe $(750-2000 \mathrm{~m})$ are suggestive of a water-column removal process 1080 of dissolved $\mathrm{Cd}$ as Cd sulfides, supporting recent studies that suggest that precipitation of $1081 \mathrm{CdS}$ in low-oxygen waters may be an important worldwide process for the marine $\mathrm{Cd}$ 1082 budget (Janssen et al., 2014). A lack of correspondingly strong evidence for CdS in low1083 oxygen waters at San Pedro may be related to the availability of suitable organic 1084 particulate micro-environments, but also highlights the fact that the metal sulfide removal 1085 hypothesis is not yet completely understood.

$1087 \mathrm{Zn}$, by comparison to $\mathrm{Cd}$, is more complicated, with several additional processes likely to 1088 be affecting the distribution of $\mathrm{Zn}$ and $\delta^{66} \mathrm{Zn}$ at both locations. At SAFe, light $\delta^{66} \mathrm{Zn}$ in 1089 surface waters $<500 \mathrm{~m}$, and a small mid-depth $\delta^{66} \mathrm{Zn}$ maximum at $750-1000 \mathrm{~m}$ set against 1090 a deep water $\delta^{66} \mathrm{Zn}$ value of $+0.5 \%$ provide further evidence for the hypothesis that 1091 scavenging of heavy $\mathrm{Zn}$ in the subsurface and regeneration of this at intermediate depths 1092 may be influencing the vertical distribution of $\mathrm{Zn}$ in the oceans. These processes may 1093 help to explain the silicate-like deeper-regeneration of $\mathrm{Zn}$ in the oceans. Evidence for the 1094 idea that $\mathrm{Zn}$ precipitates as $\mathrm{ZnS}$ in low-oxygen waters (Janssen and Cullen, 2015) is scant 1095 at both locations in this study, but remains a possibility that could also be invoked to 1096 explain mid-depth heavier $\delta^{66} \mathrm{Zn}$ at SAFe. Lastly, $\mathrm{Zn} *$ and $\delta^{66} \mathrm{Zn}$ data from San Pedro 1097 show that dissolved $\mathrm{Zn}$ in the deep silled basin is strongly affected by the addition of light 1098 Zn from low-oxygen sediments, as has previously been shown for Fe (John et al., 2012). 1099 Sporadic eddy-driven upwelling of water from deep waters in these restricted Californian 
1100 basins may therefore provide a source of $\mathrm{Zn}$, as well as Fe, to surface waters both from 1101 deep water and margin sediments. It is also interesting to note that there is no 1102 corresponding evidence for Cd release from sediments, a pattern repeated in the North 1103 Atlantic where both oxic and reductive sediments are sources of $\mathrm{Zn}$ and $\mathrm{Fe}$ but not $\mathrm{Cd}$ 1104 (Conway and John, 2014a; 2014b; 2015). Like Fe, Zn may potentially be carried within 1105 the surface California Current along the North American Margin or into the North 1106 Pacific, with potential implications for patterns of primary productivity. Although, there 1107 is no evidence of Californian sedimentary-margin $\mathrm{Zn}$ reaching the SAFe station, we do 1108 find elevated $\mathrm{Zn}^{*}(+1)$ in NPIW at SAFe which suggests that sedimentary Zn can be 1109 transported over long distances and may be an important consideration for the oceanic $\mathrm{Zn}$ 1110 cycle.

1111

\section{Acknowledgements}

1114 The data presented in this study are available as Supplementary Data. We thank the 1115 Captain, crew and sampling team on board GEOTRACES IC2 in the North Pacific, and J.

1116 Mendez, J. Moffett, J. F. Adkins for their involvement in the original collection of the 1117 San Pedro Basin water samples used in this study. We also thank Angela Rosenberg for 1118 technical assistance, Jessica Fitzsimmons for useful discussions about Pacific Fe and 1119 water masses, and Claudia Benitez-Nelson for providing San Pedro dissolved nutrient 1120 data. We appreciated the insightful comments made by two anonymous reviewers and 1121 Associate Editor Claudine Stirling, which helped us to refine our thinking and improve 1122 this manuscript. This study was funded by NSF Grant OCE-1235150.

\section{References}

1125

1126

1127

1128

1129

1130

1131
Abe K. (2002) Preformed $\mathrm{Cd}$ and $\mathrm{PO}_{4}$ and the relationship between the two elements in the northwestern Pacific and the Okhotsk Sea. Mar. Chem. 79, 27-36. doi:10.1016/S0304-4203(02)00038-5

Abouchami W., Galer S. J. G., de Baar H. J. W., Middag R., Vance D., Zhao Y., Klunder M., Mezger K., Feldmann H. and Andreae M. O. (2014) Biogeochemical cycling of cadmium isotopes in the Southern Ocean along the Zero Meridian. Geochim. Cosmochim. Acta 127, 348-367. doi: 10.1016/S0304-4203(02)00038-5 
1132

1133

1134

1135

1136

1137

1138

1139

1140

1141

1142

1143

1144

1145

1146

1147

1148

1149

1150

1151

1152

1153

1154

1155

1156

1157

1158

1159

1160

1161

1162

1163

1164

1165

Archer C., Vance D. and Butler I. B. (2004) Abiotic Zn isotope fractionations associated with ZnS precipitation. Geochim. Cosmochim. Acta 68, A325-A325. doi: 10.1016/j.gca.2004.05.008.

Archer D. E. and Johnson K. (2000) A Model of the iron cycle in the ocean. Glob. Biogeochem. Cyc. 14, 269-279. doi: 10.1029/1999GB900053

Aumont O., Maier-Reimer E., Blain S. and Monfray P. (2003) An ecosystem model of the global ocean including Fe, Si, P colimitations. Glob. Biogeochem. Cyc. 17, 1060. doi: $10.1029 / 2001 \mathrm{~GB} 001745$

Baars O., Abouchami W., Galer S. J. G., Boye M. and Croot P. L. (2014) Dissolved cadmium in the Southern Ocean: Distribution, speciation, and relation to phosphate. Limnol. Oceanogr. 59, 385-399. doi: 10.4319/lo.2014.59.2.0385

Beard B. L., Johnson C. M., Von Damm K. L. and Poulson R. L. (2003) Iron isotope constraints on Fe cycling and mass balance in oxygenated Earth oceans. Geology 31, 629-632. doi:10.1130/0091-7613(2003)031\%3C0629:IICOFC\%3E2.0.CO;2

Bennett S. A., Rouxel O. J., Schmidt K., Garbe-Schonberg D., Statham P. J. and German C. R. (2009) Iron isotope fractionation in a buoyant hydrothermal plume, $5^{\circ} \mathrm{S}$ MidAtlantic Ridge. Geochim. Cosmochim. Acta 73, 5619-5634. doi:10.1016/j.gca.2009.06.027

Bermin J., Vance D., Archer C. and Statham P. J. (2006) The determination of the isotopic composition of $\mathrm{Cu}$ and $\mathrm{Zn}$ in seawater. Chem. Geol. 226, 280-297. doi:10.1016/j.chemgeo.2005.09.025

Biller D. V. and Bruland K. W. (2013) Sources and distributions of Mn, Fe, Co, Ni, Cu, $\mathrm{Zn}$, and $\mathrm{Cd}$ relative to macronutrients along the central California coast during the spring and summer upwelling season. Mar. Chem. 155, 50-70. doi:10.1016/j.chemgeo.2005.09.025

Biller D. V. and Bruland K. W. (2014) The central California Current transition zone: A broad region exhibiting evidence for iron limitation. Prog. Oceanogr. 120, 370-382. doi: 10.1016/j.pocean.2013.11.002

Boyle E. A. and Jenkins W. J. (2008) Hydrothermal iron in the deep western South Pacific. Geochim. Cosmochim. Acta 72, A107.

Boyle E. A., Sclater F. and Edmond J. M. (1976) On the marine geochemistry of cadmium. Nature. 263, 42-44. doi: 10.1038/263042a0

Boyle E. A., Bergquist B., Kayser R. A. and Mahowald N. M. (2005) Iron, manganese, and lead at Hawaii Ocean Time-series station ALOHA: Temporal variability and an 
intermediate water hydrothermal plume. Geochim. Cosmochim. Acta 69, 933-952. doi: 10.1016/j.gca.2004.07.034

1168

1169

1170

1171

1172

1173

1174

1175

1176

1177

1178

1179

1180

1181

1182

1183

1184

1185

1186

1187

1188

1189

1190

1191

1192

1193

1194

1195

1196

1197

1198

1199 Conway T. M. and John S. G. (2014a) Quantification of dissolved iron sources to the 1200

Boyle E. A., John S. G., Abouchami W., Adkins J. F., Echegoyen-Sanz Y., Ellwood M. J., Flegal A. R., Fornace K., Gallon C. and Galer S. J. G. (2012) GEOTRACES IC1 (BATS) contamination-prone trace element isotopes $\mathrm{Cd}, \mathrm{Fe}, \mathrm{Pb}, \mathrm{Zn}, \mathrm{Cu}$, and $\mathrm{Mo}$ intercalibration. Limnol. Oceanogr.-Meth. 10, 653-665. doi:10.4319/lom.2012.10.653

Bruland K. W. (1980) Oceanographic distributions of cadmium, zinc, nickel, and copper in the North Pacific. Earth Planet. Sci. Lett. 47, 176-198. doi:10.1016/0012$821 \times(80) 90035-7$

Bruland K. W., Knauer G. A. and Martin J. H. (1978a) Cadmium in northeast Pacific Waters. Limnol. Oceanogr. 23, 618-625. doi: 10.4319/lo.1978.23.4.0618

Bruland K. W., Knauer G. A. and Martin J. H. (1978b) Zinc in Northeast Pacific water. Nature 271, 741-743. doi:10.1038/271741a0

Bruland K. W., Rue E. L. and Smith G. J. (2001) Iron and macronutrients in California coastal upwelling regimes: Implications for diatom blooms. Limnol. Oceanogr. 46, 1661-1674. doi:10.4319/lo.2001.46.7.1661

Cameron V. and Vance D. (2014) Heavy nickel isotope compositions in rivers and the oceans. Geochim. Cosmochim. Acta 128, 195-211. doi:10.1016/j.epsl.2005.05.022

Chapman J. B., Mason T. F. D., Weiss D. J., Coles B. J. and Wilkinson J. J. (2006) Chemical separation and isotopic variations of $\mathrm{Cu}$ and $\mathrm{Zn}$ from five geological reference materials. Geostand. Geoanalytical Res. 30, 5-16. doi:10.1111/j.1751908X.2006.tb00907.x

Chu N. C., Johnson C. M., Beard B. L., German C. R., Nesbitt R. W., Frank M., Bohn M., Kubik P. W., Usui A. and Graham I. (2006) Evidence for hydrothermal venting in Fe isotope compositions of the deep Pacific Ocean through time. Earth Planet. Sci. Lett. 245, 202-217. 0.1016/j.epsl.2006.02.043

Coale K. H., Johnson K. S., Fitzwater S. E., Gordon R. M., Tanner S., Chavez F. P., Ferioli L., Sakamoto C., Rogers P., Millero F. J., Steinberg P., Nightingale P., Cooper D., Cochlan W. P., Landry M. R., Constantinou J., Rollwagen G., Trasvina A. and Kudela R. M. (1996) A massive phytoplankton bloom induced by an ecosystem-scale iron fertilization experiment in the equatorial Pacific Ocean. Nature 383, 495-501. doi:10.1038/383495a0

North Atlantic Ocean. Nature 511, 212-215. doi:10.1038/nature13482 
1201 Conway T. M. and John S. G. (2014b) The biogeochemical cycling of zinc and zinc isotopes in the North Atlantic Ocean. Glob. Biogeochem. Cyc. 28, 1111-1128 doi:10.1002/2014GB004862

Conway T. M. and John S. G. (2015) Biogeochemical cycling of cadmium isotopes along a high-resolution section through the North Atlantic Ocean. Geochim. Cosmochim. Acta 148, 269-283. doi:10.1016/j.gca.2014.09.032 precise determination of iron, zinc and cadmium stable isotope ratios in seawater by double-spike mass spectrometry. Anal. Chim. Acta 793, 44-52. doi:10.1016/j.aca.2013.07.025

Coutard A., Meheut M., Vers J., Rols J.-L. and Pokrovsky O. S. (2014). Zn isotope fractionation during interaction with phototrophic biofilm. Chem. Geol. 390, 46-60. doi:10.1016/j.chemgeo.2014.10.004

Cutter G. A. and Bruland K. W. (2012) Rapid and noncontaminating sampling system for trace elements in global ocean surveys. Oceanogr. Limnol.-Meth. 10, 425-436. doi:10.4319/lom.2012.10.425 Silicon stable isotope distribution traces Southern Ocean export of Si to the eastern South Pacific thermocline. Biogeosciences 9, 4199-4213. doi: 10.5194/bg-9-41992012

de Souza G. F., Reynolds B. C., Rickli J., Frank M., Saito M. A., Gerringa L. J. A. and Bourdon B. (2012) Southern Ocean control of silicon stable isotope distribution in the deep Atlantic Ocean. Glob. Biogeochem. Cyc. 26, doi:10.1029/2011GB004141

Dideriksen K., Baker J. A., and Stipp S. L. S. (2008). Equilibrium Fe isotope fractionation between inorganic aqueous $\mathrm{Fe}$ (III) and the siderophore complex, $\mathrm{Fe}$ (III)-desferrioxamine B. Earth Planet. Sci. Lett., 269, 280-290. doi:10.1016/S03044203(97)00043-1

Elrod V. A., Berelson W. M., Coale K. H. and Johnson K. S. (2004) The flux of iron from continental shelf sediments: A missing source for global budgets. Geophys. Res. Lett. 31, L12307. doi:10.1029/2004GL020216

Ellwood M. J., Hutchins D. A., Lohan M. C., Milne A., Nasemann P., Nodder S. D., Sander S. G., Strzepek R., Wilhelm S. W. and Boyd, P. W. (2015). Iron stable isotopes track pelagic iron cycling during a subtropical phytoplankton bloom. Proceedings of the National Academy of Sciences, 112(1), E15-E20. doi: 10.1073/pnas.1421576112 
1236

1237

1238

1239

1240

1241

1242

1243

1244

1245

1246

1247

1248

1249

1250

1251

1252

1253

1254

1255

1256

1257

1258

1259

1260

1261

1262

1263

1264

1265

1266

1267

1268

1269

1270

Fitzsimmons J. N., Conway T. M., John S. G. and Boyle E. A. (2013) Iron isotopes in seawater from the Southeast Pacific and North Atlantic Oceans. Mineral. Mag. 77, 1092.

Fitzsimmons J. N., Boyle E. A., \& Jenkins W. J. (2014). Distal transport of dissolved hydrothermal iron in the deep South Pacific Ocean. Proc. Natl. Acad. Sci. 111, 16654-16661. doi: 10.1073/pnas.1418778111

Homoky W. B., John S. G., Conway T. M. and Mills R. A. (2013) Distinct iron isotopic signatures and supply from marine sediment dissolution. Nat. Comm. 4, 2143. doi:10.1038/ncomms3143

Homoky W. B., Severmann S., Mills R. A., Statham P. J. and Fones G. R. (2009) Porefluid Fe isotopes reflect the extent of benthic Fe redox recycling: Evidence from continental shelf and deep-sea sediments. Geology 37, 751-754. doi:10.1130/G25731A.1

Horner T. J., Lee R. B. Y., Henderson G. M. and Rickaby R. E. M. (2013) Nonspecific uptake and homeostasis drive the oceanic cadmium cycle. Proc. Natl. Acad. Sci. 110, 2500-2505. doi:10.1073/pnas. 1213857110

Horner, T. J., Williams, H. M., Hein, J. R., Saito, A. M., Burton, K. W., Halliday, A. N. and Nielsen, S. G. (2014) Persistence of deeply sourced iron in the Pacific Ocean. Proc. Natl. Acad. Sci. 112, 1292-1297. doi:10.1073/pnas.1420188112

Janssen D. J. and Cullen J. T. (2015) Decoupling of zinc and silicic acid in the subarctic northeast Pacific interior. Mar. Chem. In press. doi:10.1016/j.marchem.2015.03.014

Janssen D. J., Conway T. M., John S. G., Christian J., Kramer D. I., Pederson T. F. and Cullen J. T. (2014) An undocumented water column sink for cadmium in open ocean oxygen deficient zones. Proc. Natl. Acad. Sci. 111, 6888-6893. doi:10.1073/pnas.1402388111

Jeandel C., Peucker-Ehrenbrink B., Jones M., Pearce C., Oelkers E. H., Godderis Y., Lacan F., Aumont O. and Arsouze T. (2011) Ocean margins: The missing term in oceanic element budgets? Eos Trans. AGU 92, 217. doi:10.1029/2011EO260001

Jickells T. D., An Z. S., Andersen K. K., Baker A. R., Bergametti G., Brooks N., Cao J. J., Boyd P. W., Duce R. A., Hunter K. A., Kawahata H., Kubilay N., laRoche J., Liss P. S., Mahowald N. M., Prospero J. M., Ridgwell A. J., Tegen I. and Torres R. (2005) Global iron connections between desert dust, ocean biogeochemistry, and climate. Science 308, 67-71. doi: 10.1126/science.1105959

John S. G. (2007) Marine biogeochemistry of zinc isotopes. Ph. D. Thesis, Woods Hole Oceanographic Institution \& Massachusetts Institute of Technology. 
1271

1272

1273

1274

1275

1276

1277

1278

1279

1280

1281

1282

1283

1284

1285

1286

1287

1288

1289

1290

1291

1292

1293

1294

1295

1296

1297

1298

1299

1300

1301

1302

1303

1304

John S. G. and Adkins J. F. (2012) The vertical distribution of iron stable isotopes in the North Atlantic near Bermuda. Glob. Biogeochem. Cyc. 26, GB2034. doi:10.1029/2011GB004043

John S. G. and Conway T. M. (2014) A role for scavenging in the marine biogeochemical cycling of zinc and zinc isotopes. Earth Planet. Sci. Lett. 394, 159-167. doi: 10.1016/j.epsl.2014.02.053

John S. G., Geis R. W., Saito M. A. and Boyle E. A. (2007a) Zinc isotope fractionation during high-affinity and low-affinity zinc transport by the marine diatom Thalassiosira oceanica. Limnol. Oceanogr. 52, 2710-2714. doi: 10.4319/lo.2007.52.6.2710

John S. G., Genevievepark J., Zhang Z., Boyle E. A., Park J. G. and Zhan Z. T. (2007b) The isotopic composition of some common forms of anthropogenic zinc. Chem. Geol. 245, 61-69. doi:10.1016/j.chemgeo.2007.07.024

John S. G., Mendez J., Moffett J. W. and Adkins J. F. (2012) The flux of iron and iron isotopes from San Pedro Basin sediments. Geochim. Cosmochim. Acta 93, 14-29. doi:10.1016/j.gca.2012.06.003

Johnson C. M., Skulan J. L., Beard B. L., Sun H., Nealson K. H., Braterman, P. S. (2002). Isotopic fractionation between $\mathrm{Fe}(\mathrm{III})$ and $\mathrm{Fe}(\mathrm{II})$ in aqeous solutions. Earth Planet. Sci. Lett. 195, 141-153. doi:10.1016/S0012-821X(01)00581-7

Johnson K. S., Gordon R. M. and Coale, K. H. (1997) What controls dissolved iron concentrations in the world ocean? Mar. Chem. 57, 137-161. doi:10.1016/S03044203(97)00043-1

Johnson K. S., Chavez F. P. and Friederich G. E. (1999) Continental-shelf sediment as a primary source for coastal phytoplankton. Nature. 398, 697-700. doi: 10.1038/19511

Johnson K., Boyle E. A., Bruland K. W., Coale K. H., Measures C. I., Moffett J. W., Aguilar-Islas A. M., Barbeau K., Bergquist B., Bowie A. R., Buck K., Cai Y., Chase Z., Cullen J., Doi T., Elrod V. A., Fitzwater S., Gordon M., King A., Laan P., Baquer L., Landing W. M., Lohan M. C., Mendez J., Milne A., Obata H., Ossiander L., Plant J., Sarthou G., Sedwick P. N., Smith G., Sohst B., Tanner S., Berg S. Van den and Wu J. F. (2007) Developing standards for dissolved iron in seawater. Eos Trans. AGU 88, 131-132. doi:10.1029/2007EO110003

Kim T., Obata H., Kondo Y., Ogawa H. and Gamo T. (2015) Distribution and speciation of dissolved zinc in the western North Pacific and its adjacent seas. Mar. Chem. In press. http://dx.doi.org/10.1016/j.marchem.2014.10.016 
1305

1306

1307

1308

1309

1310

1311

1312

1313

1314

1315

1316

1317

1318

1319

1320

1321

1322

1323

1324

1325

1326

1327

1328

1329

1330

1331

1332

1333

1334

1335

1336

1337

1338

1339

King A. L. and Barbeau K. A. (2011) Dissolved iron and macronutrient distributions in the southern California Current System. J. Geophys. Res. 116, C03018. doi:10.1029/2010JC006324

Koroleff F. (1983) Determination of nutrients. In Methods of Seawater Analysis (eds. K. Grasshof, M. Ehrherd, and K. Kremling). Verlag Chemie, Weinheim. pp. 125-125.

Labatut M., Lacan F., Pradoux C., Chmeleff J., Radic A., Murray J. W., Poitrasson F., Johansen A. M. and Thil F. (2014) Iron sources and dissolved-particulate interactions in the seawater of the Western Equatorial Pacific, iron isotope perspective. Glob. Biogeochem. Cyc. 28, 1044-1065 doi:10.1002/2014GB004928

Lacan F., Francois R., Ji Y. C. and Sherrell R. M. (2006) Cadmium isotopic composition in the ocean. Geochim. Cosmochim. Acta 70, 5104-5118. doi:10.1002/2014GB004928

Lacan F., Radic A., Jeandel C., Poitrasson F., Sarthou G., Pradoux C. and Freydier R. (2008) Measurement of the isotopic composition of dissolved iron in the open ocean. Geophys. Res. Lett. 35, L24610. doi:10.1029/2008GL035841

Little S. H., Vance D., Walker-Brown C. and Landing W. M. (2014) The oceanic mass balance of copper and zinc isotopes, investigated by analysis of their inputs, and outputs to ferromanganese oxide sediments. Geochim. Cosmochim. Acta 125, 673693. doi:10.1029/2008GL035841

Lupton J. (1998) Hydrothermal helium plumes in the Pacific Ocean. J. Geophys. Res. 103, 15853-15868. doi:10.1029/98JC00146

Lynn R. J. and Simpson J. J. (1987) The California Current system: The seasonal variability of its physical characteristics. J. Geophys. Res. 92, 12947. doi:10.1029/JC092iC12p12947

Maréchal C. N., Nicolas E., Douchet C. and Albarède F. (2000) Abundance of zinc isotopes as a marine biogeochemical tracer. Geochem. Geophys. Geosys. 1, 1015. doi:10.1029/1999GC000029

Moore J. K. and Braucher O. (2008) Sedimentary and mineral dust sources of dissolved iron to the world ocean. Biogeosci. 5, 631-656. doi:10.5194/bg-5-631-2008

Moore J. K., Doney S. C., Glover D. M. and Fung I. Y. (2001) Iron cycling and nutrientlimitation patterns in surface waters of the World Ocean. Deep. Sea Res. Pt II 49, 463-507. doi:10.1016/S0967-0645(01)00109-6

Moore J. K., Doney S. C. and Lindsay K. (2004) Upper ocean ecosystem dynamics and iron cycling in a global three-dimensional model. Glob. Biogeochem. Cyc. 18, GB4028. doi:10.1029/2004GB002220 
Morel F. M. M. and Price N. M. (2003) The biogeochemical cycles of trace metals in the oceans. Science 300, 944-7. doi:10.1126/science. 1083545

1342

1343

1344

1345

1346

1347

1348

1349

1350

1351

1352

1353

1354

1355

1356

1357

1358

1359

1360

1361

1362

1363

1364

1365

1366

1367

1368

1369

1370

1371

1372

1373

1374

1375
Morgan J. L., Wasylenki L. E., Nuester J., and Anbar A. D. (2010). Fe Isotope Fractionation during Equilibration of $\mathrm{Fe}-$ Organic Complexes. Environmental science \& technology, 44(16), 6095-6101. doi:10.1021/es100906z

Nishioka J., Ono T., Saito H., Nakatsuka T., Takeda S., Yoshimura T., Suzuki K., Kuma K., Nakabayashi S., Tsumune D., Mitsudera H., Johnson W. K. and Tsuda A. (2007) Iron supply to the western subarctic Pacific: Importance of iron export from the Sea of Okhotsk. J. Geophys. Res. 112, C10012. doi:10.1029/2006JC004055

Parekh P., Follows M. J. and Boyle E. A. (2004) Modeling the global ocean iron cycle. Glob. Biogeochem. Cyc. 18, GB1002. doi:10.1029/2003GB002061

Radic A., Lacan F. and Murray J. W. (2011) Iron isotopes in the seawater of the equatorial Pacific Ocean: New constraints for the oceanic iron cycle. Earth Planet. Sci. Lett. 306, 1-10. doi:10.1016/j.epsl.2011.03.015

Rehkämper M., Wombacher F., Horner T. J. and Xue Z. (2012) Natural and anthropogenic Cd isotope variations. In: Handbook of Environmental Isotope Geochemistry Advances in Isotope Geochemistry. pp. 125-154. doi:10.1007/978-3642-10637-8_8.

Ripperger S. and Rehkämper M. (2007) Precise determination of cadmium isotope fractionation in seawater by double spike MC-ICPMS. Geochim. Cosmochim. Acta 71, 631-642. doi:10.1016/j.eps1.2007.07.034

Ripperger S., Rehkämper M., Porcelli D. and Halliday A. N. (2007) Cadmium isotope fractionation in seawater - A signature of biological activity. Earth Planet. Sci. Lett. 261, 670-684. doi:10.1016/j.epsl.2007.07.034

Saito M. A., Noble A. E., Tagliabue A., Goepfert T. J., Lamborg C. H. and Jenkins W. J. (2013) Slow-spreading submarine ridges in the South Atlantic as a significant oceanic iron source. Nat. Geosci. 6, 775-779. doi:10.1038/ngeo1893

Sedwick P. N., Sohst B.M., Ussher S. J., and Bowie A. R. (2015). A zonal picture of the water column distribution of dissolved iron(II) during the U.S. GEOTRACES North Atlantic transect cruise (GEOTRACES GA03). Deep Sea Res. Pt II. In press. doi:10.1016/j.dsr2.2014.11.004

Severmann S., Johnson C. M., Beard B. L., German C. R., Edmonds H. N., Chiba H. and Green D. R. H. (2004) The effect of plume processes on the Fe isotope composition of hydrothermally derived $\mathrm{Fe}$ in the deep ocean as inferred from the Rainbow vent site, Mid-Atlantic Ridge, $36^{\circ} 14^{\prime}$ N. Earth Planet. Sci. Lett. 225, 63-76. doi:10.1016/j.epsl.2004.06.001 
1376

1377

1378

1379

1380

1381

1382

1383

1384

1385

1386

1387

1388

1389

1390

1391

1392

1393

1394

1395

1396

1397

1398

1399

1400

1401

1402

1403

1404

1405

1406

1407

1408

1409

Severmann S., McManus J., Berelson W. M. and Hammond D. E. (2010) The continental shelf benthic iron flux and its isotope composition. Geochim. Cosmochim. Acta 74, 3984-4004. doi:10.1016/j.gca.2010.04.022

Skulan J. L., Beard B. L., and Johnson C. M. (2002). Kinetic and equilibrium Fe isotope fractionation between aqueousFe(III) and hematite. Geochim. Cosmochim. Acta. 66. 2995-3015. doi:10.1016/S0016-7037(02)00902-X

Staubwasser M., Schoenberg R., von Blanckenburg F., Krüger, S. and Pohl, C. (2013) Isotope fractionation between dissolved and suspended particulate $\mathrm{Fe}$ in the oxic and anoxic water column of the Batlic Sea. Biogeosci. 10, 233-245. doi:10.5194/bg-10233-2013

Tagliabue A., Bopp L. and Aumont O. (2009) Evaluating the importance of atmospheric and sedimentary iron sources to Southern Ocean biogeochemistry. Geophys. Res. Lett. 36, L13601. doi:10.1029/2009GL038914

Tagliabue A., Bopp L., Dutay J.-C. C., Bowie A. R., Chever F., Jean-Baptiste P., Bucciarelli E., Lannuzel D., Remenyi T., Sarthou G., Aumont O., Gehlen M. and Jeandel C. (2010) Hydrothermal contribution to the oceanic dissolved iron inventory. Nat. Geosci. 3, 252-256. doi:10.1038/ngeo818

Tagliabue A., Aumont O. and Bopp L. (2014) The impact of different external sources of iron on the global carbon cycle. Geophys. Res. Lett. 41, 920-926.

doi:10.1002/2013GL059059

Talley L. D. (1993) Distribution and Formation of North Pacific Intermediate Water. $J$. Phys. Oceanogr. 23, 517-537. doi:10.1175/15200485(1993)023<0517:DAFONP>2.0.CO;2

Talley L. D. (2008) Freshwater transport estimates and the global overturning circulation: Shallow, deep and throughflow components. Prog. Oceanogr. 78, 257-303. doi:10.1016/j.pocean.2008.05.001

Talley L. D., Pickard G. L., Emery W. J. and Swift J. H. (2011) Descriptive Physical Oceanography. Elsevier.

Toner B. M., Fakra S. C., Manganini S. J., Santelli C. M., Marcus M. A., Moffett J. W., Rouxel O. J., German C. R. and Edwards K. J. (2009) Preservation of iron(II) by carbon-rich matrices in a hydrothermal plume. Nat. Geosci. 2, 197-201. doi:10.1038/ngeo433

Vance. D, Zhao Y., Cullen J. and Lohan M. (2012) Zinc Isotopic Data from the NE Pacific Reveals Shallow Recycling. Mineral. Mag. 76, 2486. 
1410

1411

1412

1413

1414

1415

1416

1417

1418

1419

1420

1421

1422

1423

1424

1425

1426

1427

1428

1429

1430

1431

1432

1433

1434

1435

1436
Waeles M., Baker A. R., Jickells T. D. and Hoogewerff J. (2007) Global dust teleconnections: aerosol iron solubility and stable isotope composition. Environ. Chem. 4, 233-237. doi:10.1071/EN07013

Wu J. Wells M. L. and Rember R. (2011) Dissolved iron anomaly in the deep tropicalsubtropical Pacific: Evidence for long-range transport of hydrothermal iron. Geochim. Cosmochim. Acta 75, 460-468. doi:10.1071/EN07013

Wyatt N J., Milne A., Woodward E. M. S., Rees A. P., Browning T. J., Bouman H. A., Worsfeld P. J. and Lohan M. C. (2014) Biogeochemical cycling of dissolved zinc along the GEOTRACES South Atlantic transect GA10 at $40^{\circ}$ S. Global Biogeochem. Cyc. doi:10.1002/2013GB004637

Xue Z. C., Rehkämper M., Horner T. J., Abouchami W., Middag R., van de Flierdt T. and de Baar H. J. W. (2013) Cadmium isotope variations in the Southern Ocean. Earth Planet. Sci. Lett. 382, 161-172. doi:10.1016/j.epsl.2013.09.014

Xue Z. C., Rehkämper M., Schonbachler M., Statham P. J. and Coles B. J. (2012) A new methodology for precise cadmium isotope analyses of seawater. Anal. Bioanal. Chem. 402, 883-893. doi:10.1007/s00216-011-5487-0

Yang S.-C., Lee D.-C. and Ho T.-Y. (2012) The isotopic composition of Cadmium in the water column of the South China Sea. Geochim. Cosmochim. Acta 98, 66-77. doi:10.1016/j.gca.2012.09.022

Yucel M., Gartman A., Chan C. S. and Luther G. W. (2011) Hydrothermal vents as a kinetically stable source of iron-sulphide-bearing nanoparticles to the ocean. Nat. Geosci. 4, 367-371. doi:10.1038/ngeo1148

Zhao Y., Vance D., Abouchami W. and de Baar H. J. W. (2014) Biogeochemical cycling of zinc and its isotopes in the Southern Ocean. Geochim. Cosmochim. Acta 125, 653-672. doi: 10.1016/j.gca.2013.07.045 
1437 Figure 1. Location of SAFe station $\left(3^{\circ} \mathrm{N} 140^{\circ} \mathrm{W}\right)$ and San Pedro basin $\left(33.8^{\circ} \mathrm{N}\right.$

$\left.1438 \mathbf{1 1 8 . 4}^{\circ} \mathrm{W}\right)$ sampling sites, overlaid on either a) depth or $\delta^{3} \mathrm{He}(\%)$ at either b) $1000 \mathrm{~m}$

1439 or c) $2000 \mathrm{~m} . \delta^{3} \mathrm{He}$ contours are based on Plate 4 of Lupton (1998), with $1000 \mathrm{~m}$

1440 representing a Loihi hydrothermal source, and $2000 \mathrm{~m}$ representing the combined

1441 hydrothermal influence of Juan de Fuca and the East Pacific Rise. San Pedro is not shown

1442 overlaid on $\delta^{3} \mathrm{He}$ because San Pedro basin depth is only $900 \mathrm{~m}$.

1444 Figure 2. a) Dissolved Fe concentration and stable isotope ratio $\left(\delta^{56} \mathbf{F e}\right)$ profiles from 1445 the SAFe Station in the North East Pacific $\left(3^{\circ} \mathrm{N} \mathbf{1 4 0}^{\circ} \mathrm{W}\right.$; May 2009), with 1446 supporting dissolved data. The grey dissolved Fe data was measured in $0.4 \mu \mathrm{m}$ filtered 1447 samples collected from the same location in October 2004 (Wu et al., 2011; here 1448 converted from nmol L${ }^{-1}$ to $\mathrm{nmol} \mathrm{kg}^{-1}$ using a seawater density of 1.025). The shaded blue 1449 bar represents dissolved oxygen concentrations $<75 \mu \mathrm{mol} \mathrm{L}^{-1}$ (see Fig. 3a). Horizontal 1450 dashed lines represent delineation of water masses (see text; Talley, 2008; Talley et al., 1451 2011): North Pacific Intermediate Water (NPIW), Antarctic Intermediate Water (AAIW), 1452 Upper Circumpolar Deep Water (UCDW), Pacific Deep Water (PDW), Lower 1453 Circumpolar Deep Water (LCDW). Errors on $\delta^{56} \mathrm{Fe}$ are $2 \sigma$ internal error as calculated in 1454 the text. b) Dissolved $\boldsymbol{\delta}^{3} \mathrm{He}$ and oxygen concentrations from EWOCE $\mathbf{P 1 7}$ section 1455 (July 1991 - June 1993). The vertical thick dashed line represents the location of the 1456 SAFe station on this section.

1458 Figure 3. Dissolved a) $\mathbf{C d}$ and b) $\mathbf{Z n}$ concentrations and stable isotope ratio profiles $1459\left(\delta^{114} \mathbf{C d}\right.$ and $\left.\boldsymbol{\delta}^{66} \mathbf{Z n}\right)$ from the SAFe station in the North East Pacific $\left(\mathbf{3 0}^{\circ} \mathbf{N} \mathbf{1 4 0}^{\circ} \mathrm{W}\right)$, 1460 with supporting dissolved data. Note reduced scale for $\delta^{114} \mathrm{Cd}$ above $+1 \%$. The shaded 1461 blue bar represents dissolved oxygen concentrations $<75 \mu \mathrm{mol} \mathrm{\textrm {L } ^ { - 1 }}$. Vertical blue and 1462 purple lines represent representative $\delta^{66} \mathrm{Zn}(+0.5 \% \circ)$ and $\delta^{114} \mathrm{Cd}(+0.3 \% o)$ of the deep 1463 ocean (see text). Horizontal dashed lines represent delineation of water masses as for Fig. $14642 . \mathrm{Zn}^{*}$ and $\mathrm{Cd}^{*}$ are calculated as in the text, with 0 represented by a vertical grey line. All 1465 errors on isotope ratios are $2 \sigma$ internal error as calculated in the text. 
1467 Figure 4. Dissolved $\delta^{66} \mathrm{Zn}$ profiles from the West North Atlantic, Central North 1468 Atlantic, East North Atlantic (Conway and John, 2014b) and North East Pacific

1469 (this study; John, 2007). The vertical grey bars represent our current best estimate of the

$1470 \delta^{66} \mathrm{Zn}$ signature of the deep ocean $\mathrm{Zn}$ reservoir $(+0.50 \%$ ) calculated from the data used to

1471 calculate deep ocean means by Conway and John (2014b; $\mathrm{n}=202)$ and Zhao et al. (2014,

$1472 \mathrm{n}=21$ ). We reproduce error bars from their respective publications, with grey bars

1473 denoting either $2 \sigma$ internal error, or 2SD of the mean (for the data of John (2007)).

1474

1475 Figure 5. Dissolved a) $\mathrm{Fe}$, b) $\mathrm{Cd}$ and c) $\mathrm{Zn}$ concentration and stable isotope ratio $1476\left(\delta^{56} \mathrm{Fe}, \delta^{114} \mathrm{Cd}\right.$ and $\left.\delta^{66} \mathrm{Zn}\right)$ profiles from the San Pedro Basin close to California $1477\left(\mathbf{3 3 . 8}^{\circ} \mathbf{N} 118.4^{\circ} \mathrm{W}\right)$, with supporting dissolved data. Fe concentration, $\delta^{56} \mathrm{Fe}$, oxygen, 1478 fluorescence and temperature are reproduced from John et al. (2012). All errors on 1479 isotope ratios are $2 \sigma$ internal error as calculated in the text. $\mathrm{Zn}^{*}$ and $\mathrm{Cd}^{*}$ are calculated as 1480 in the text, with 0 marked as a vertical grey line. Sill depth is marked with a horizontal 1481 grey dashed line, deep ocean $\delta^{66} \mathrm{Zn}$ and $\delta^{114} \mathrm{Cd}$ signatures are denoted by the same 1482 vertical coloured dashed lines as in Fig. 3. The grey bar labeled CC marks the low1483 salinity horizon corresponding to the California Current at 50-100 m. 
a)
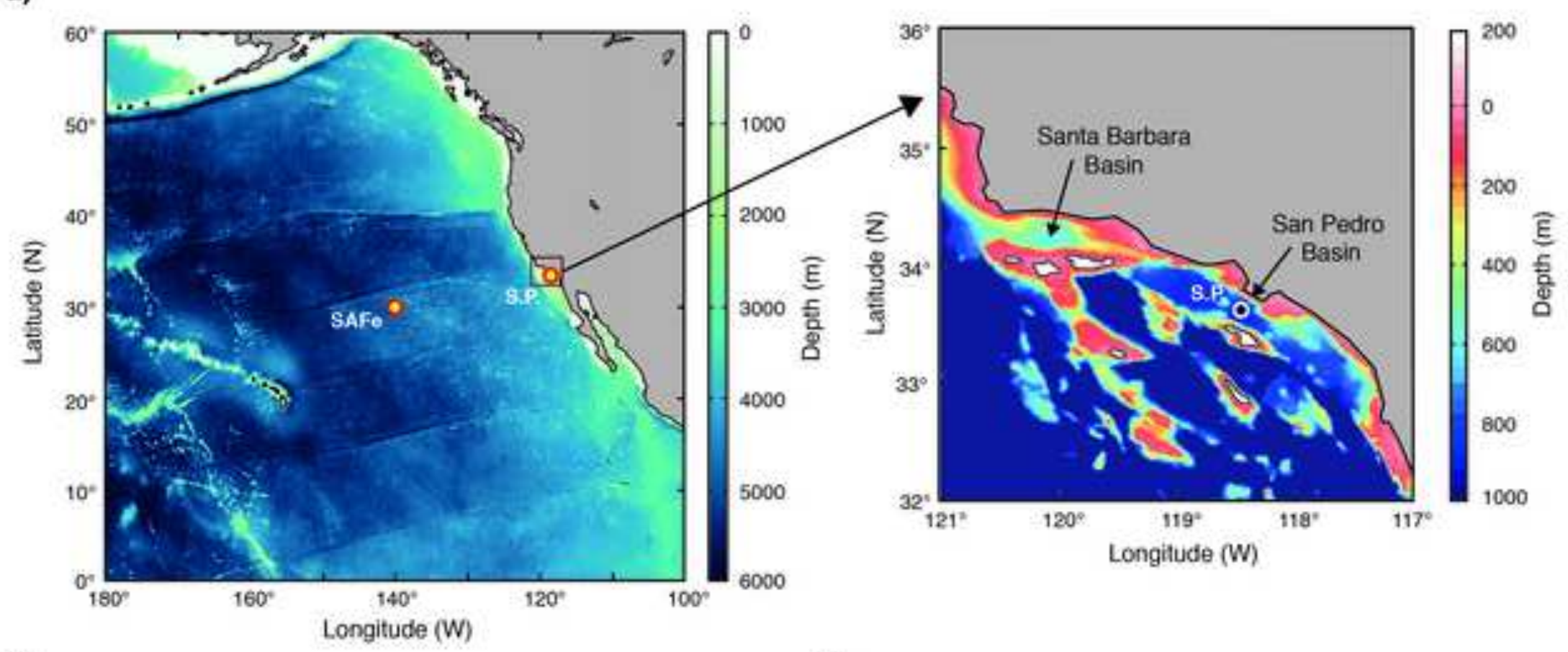

b)

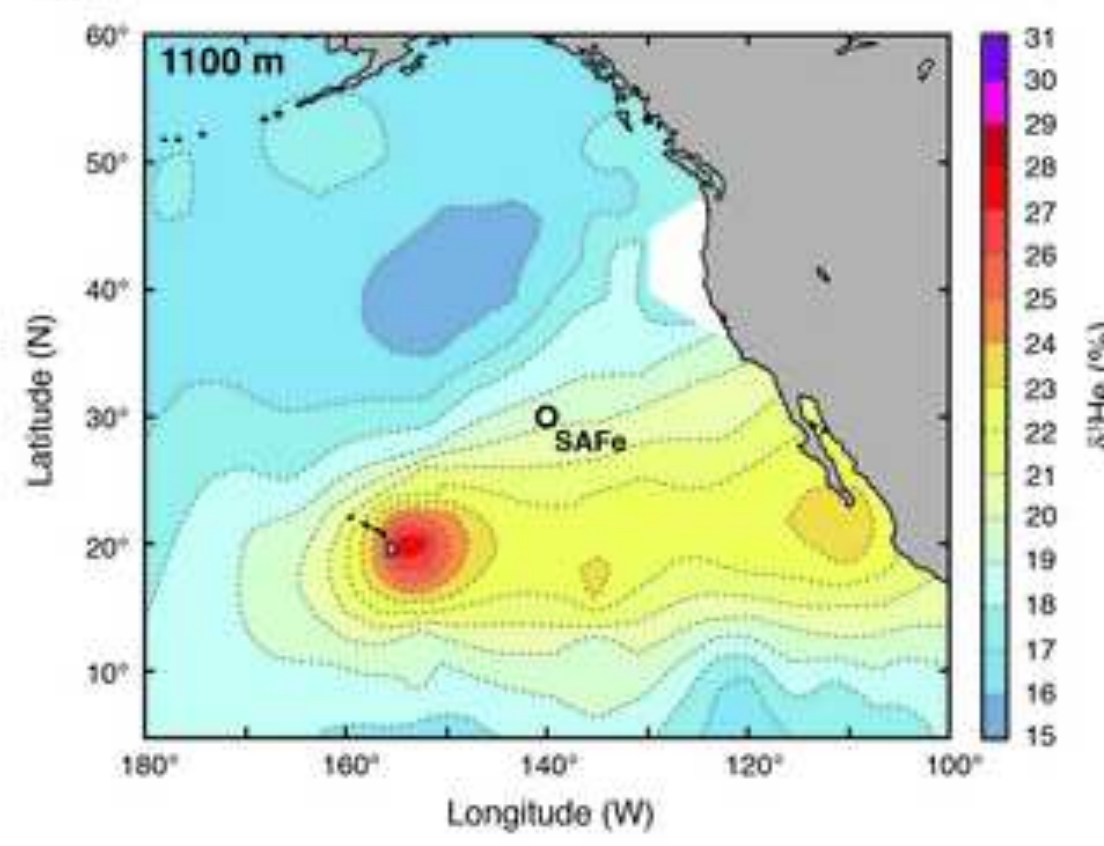

c)

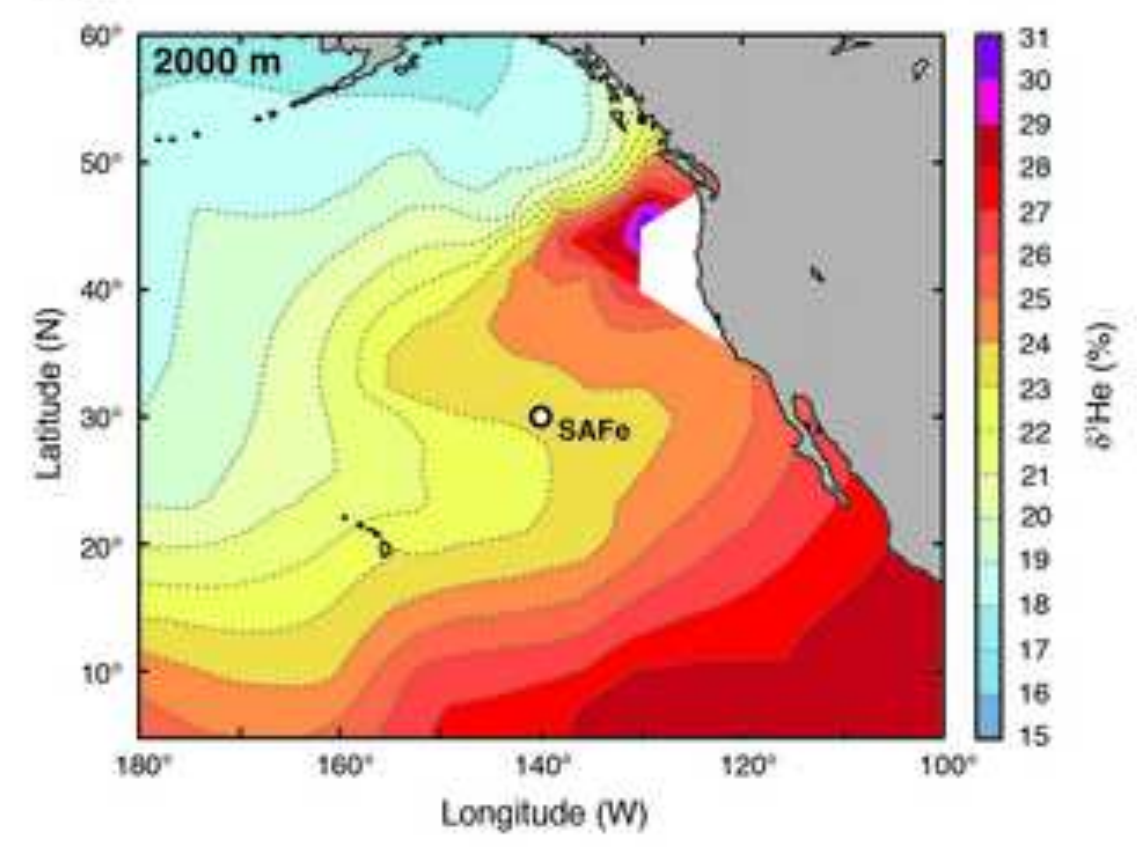


Figure 2

a) $\mathrm{Fe}$

Pot Temperative ('C)

Salinity (P.S.U)

$\mathrm{NO}_{3}$ (urnol L')
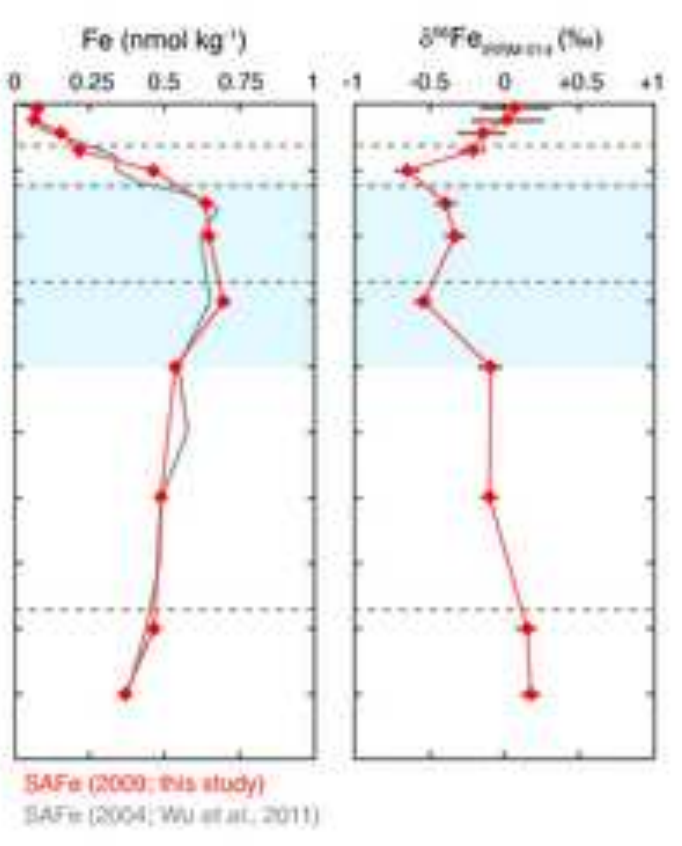

b) EWOCE P17 data
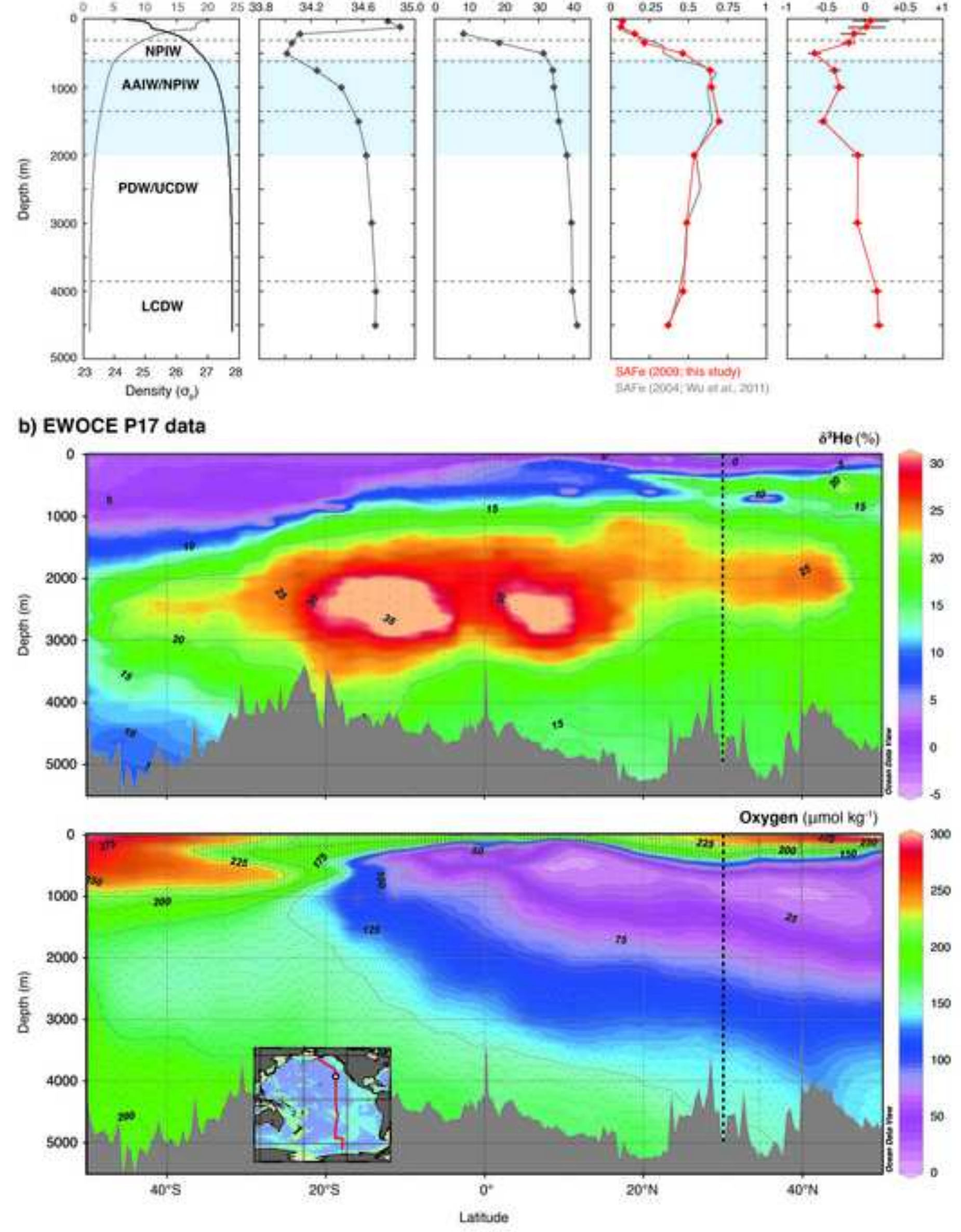

BAF" (2000, his atudy)

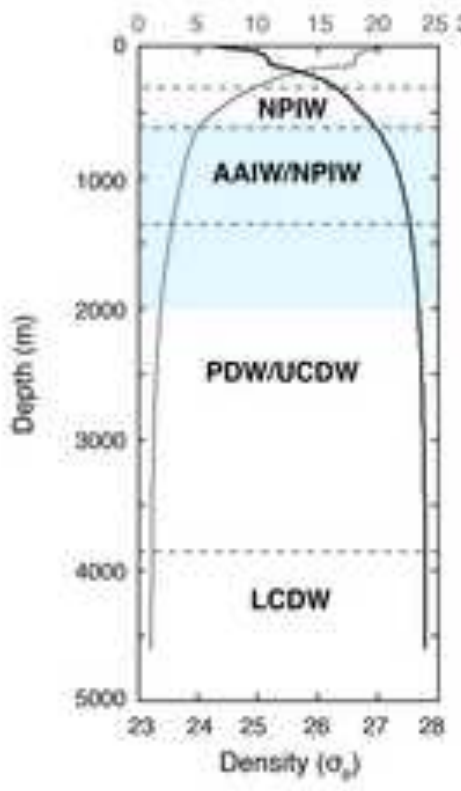


a) $\mathrm{Cd}$

O, fumol $\mathrm{kg}$ ')

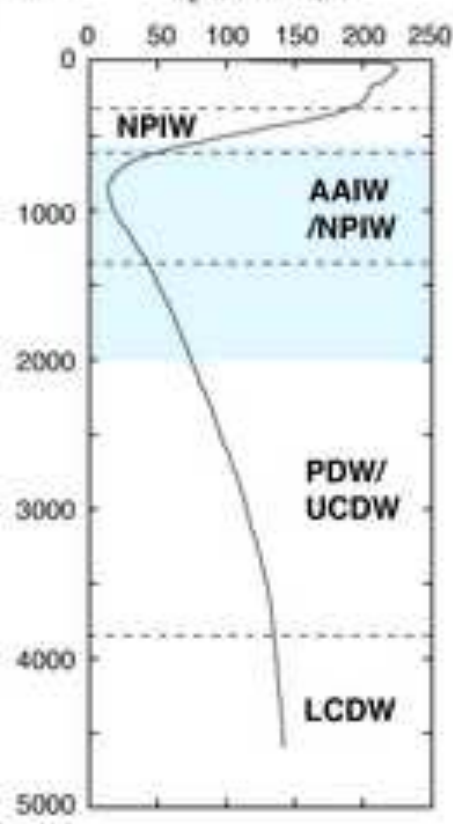

b) $\mathrm{Zn}$

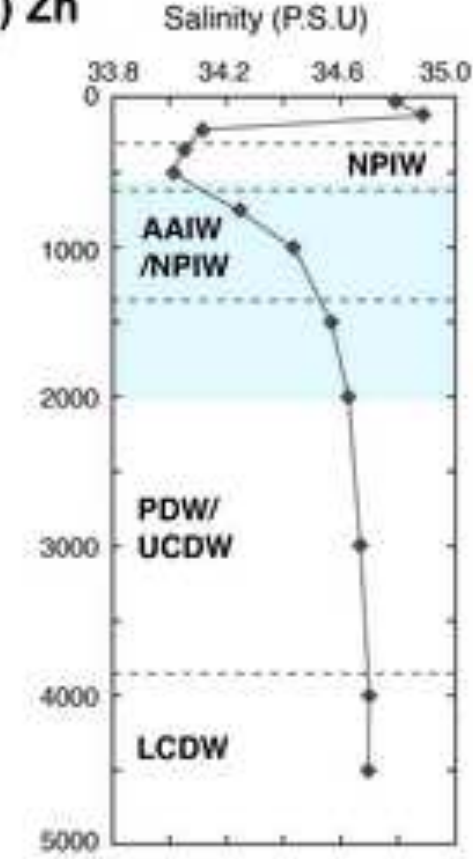

$\mathrm{PO}_{4}^{*}$ (umol L')

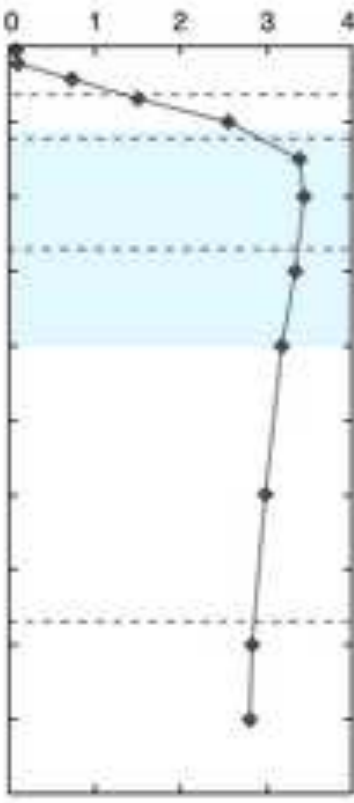

Si (jemol L')

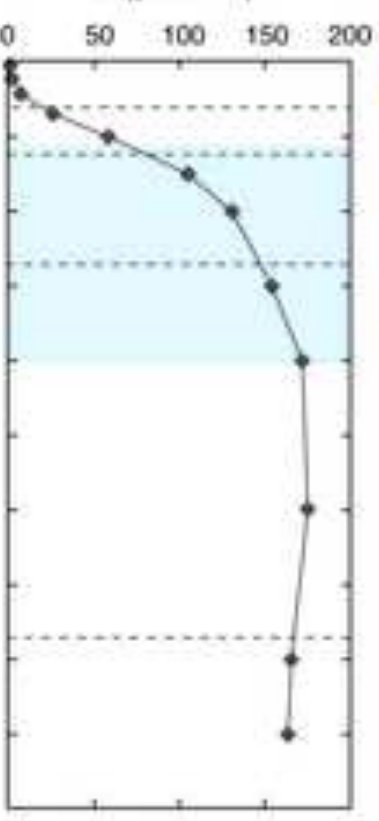

Cd (nmol kg-)

$\begin{array}{lllllllll}0 & 0.2 & 0.4 & 0.6 & 0.8 & 1.0 & 1.2 & 0\end{array}$

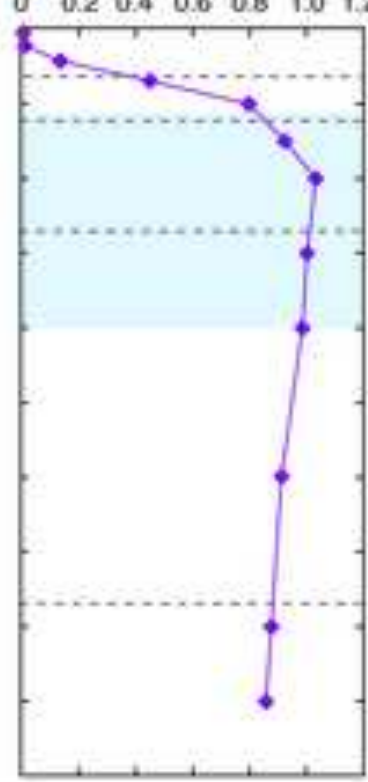

$\mathrm{Zn}$ (nmol kg')

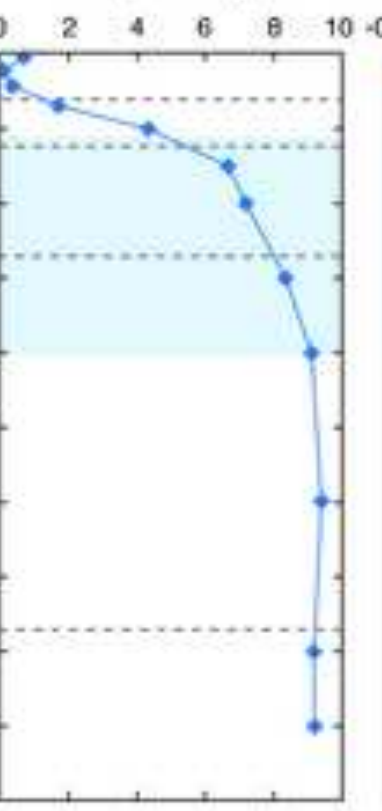

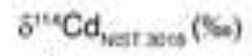

$\mathrm{Cd}^{*}$

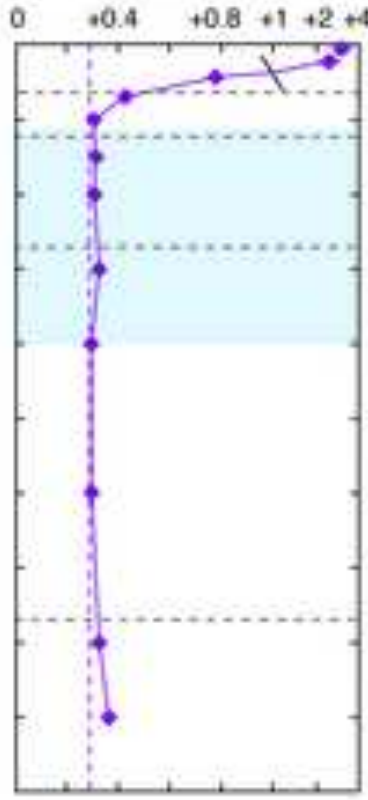

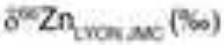

$\mathrm{Zn}^{*}$
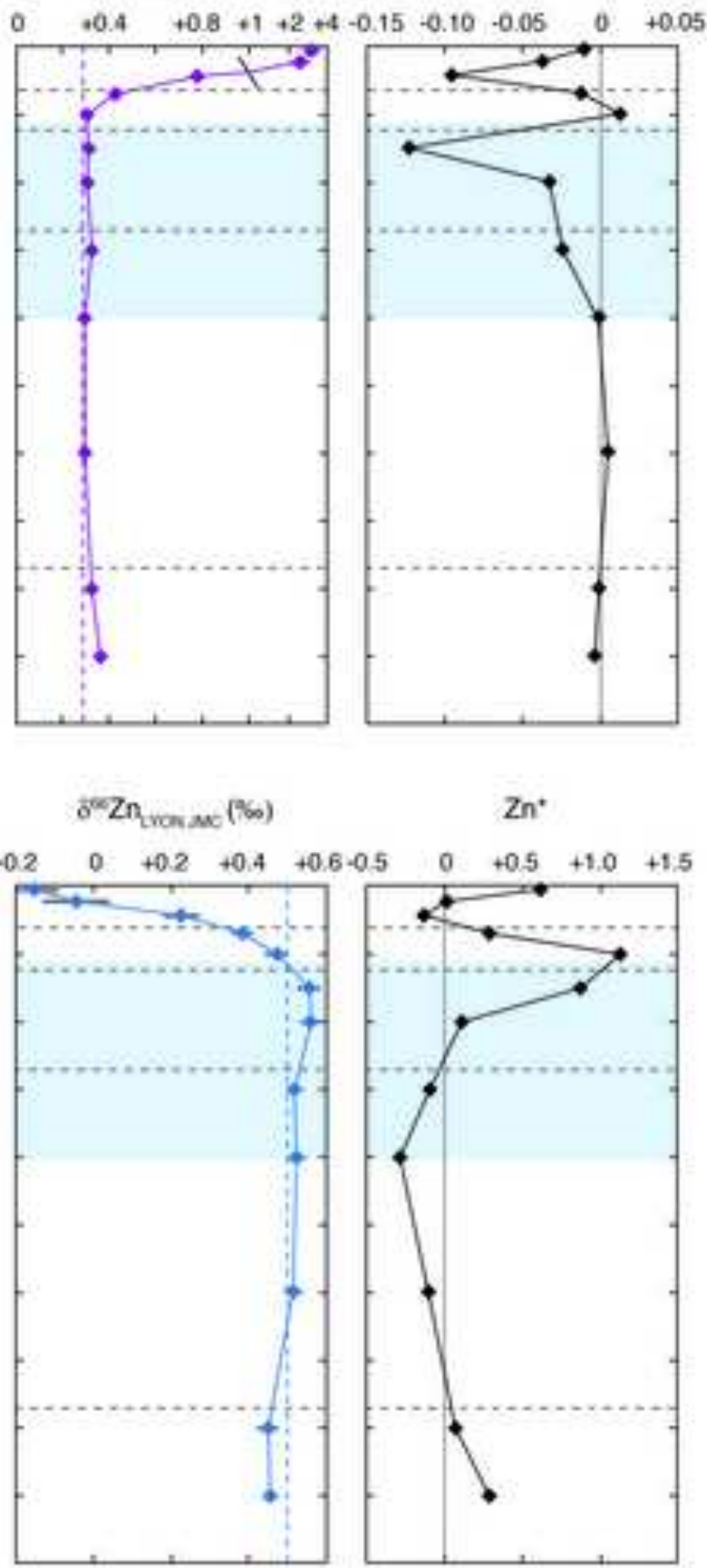


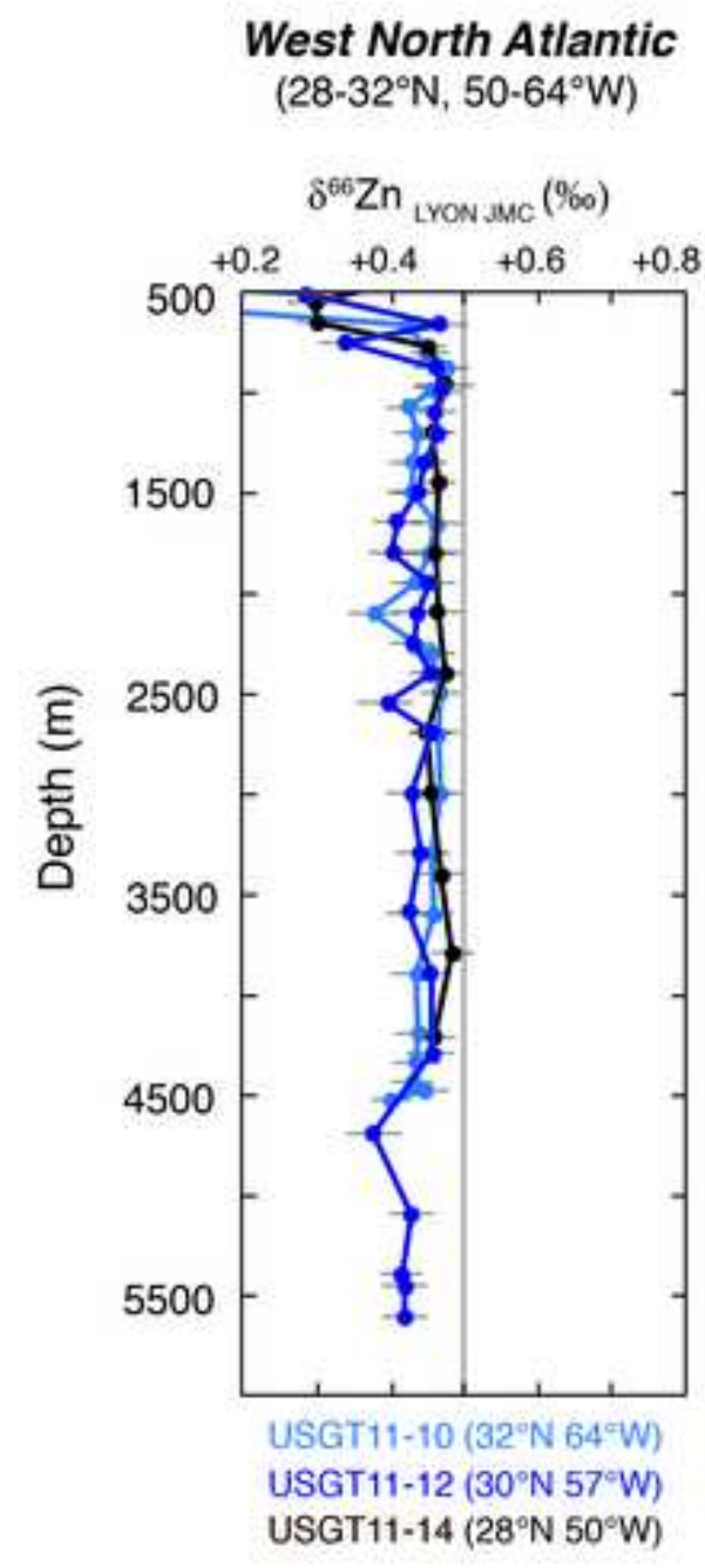

Central North Atlantic

$\left(19-24^{\circ} \mathrm{N}, 29-40^{\circ} \mathrm{W}\right)$

$\delta^{66} \mathrm{Zn}$ LYON JMC $(\%)$

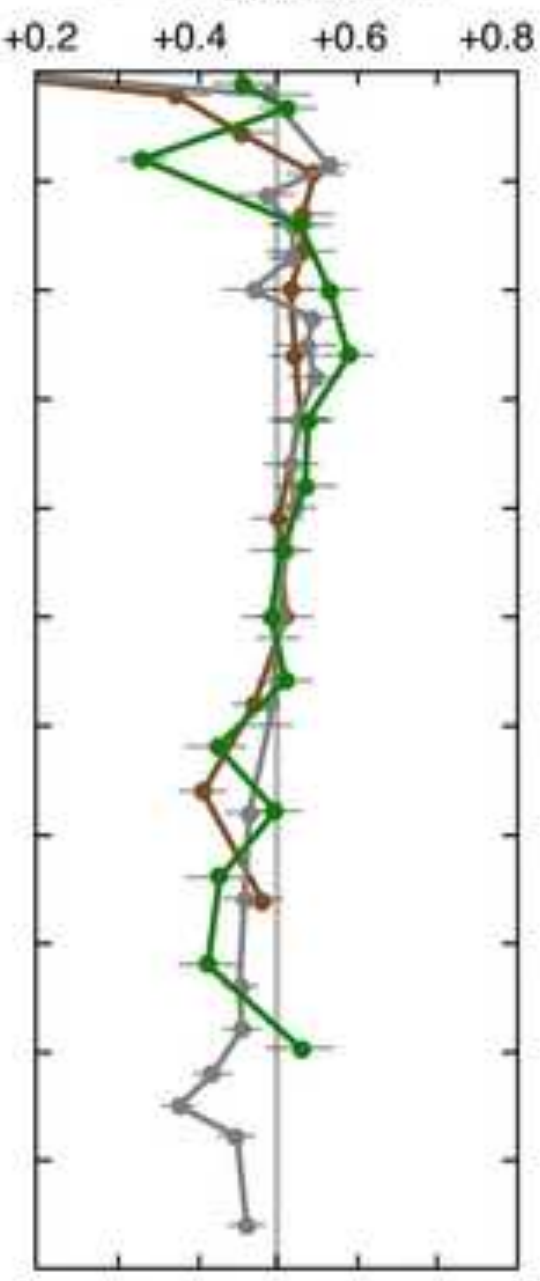

USGT11-18 $\left(24^{\circ} \mathrm{N} 40^{\circ} \mathrm{W}\right)$ USGT11-20 (22. $\left.\mathrm{N} 36^{\circ} \mathrm{W}\right)$ USGT11-22 (19 ${ }^{\circ}$ 29 $\left.\mathrm{W}\right)$
East North Atlantic

$\left(17.4^{\circ} \mathrm{N}, 18-25^{\circ} \mathrm{W}\right)$

$\delta^{66} \mathrm{Zn}$ iYon Juc $(\%)$

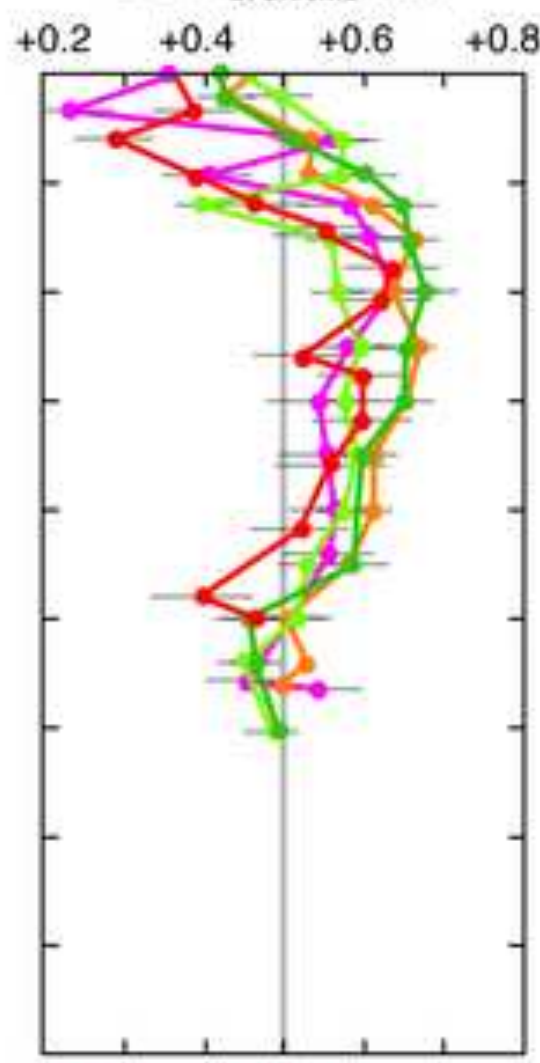

USGT10.9 (17.4 $\left.{ }^{\circ} \mathrm{N} 18.3^{\mathrm{b}} \mathrm{W}\right)$ USGT10-10 $\left(17.4^{4} \mathrm{~N} 20.8^{\circ} \mathrm{W}\right)$ USGT10-11 (17.4 N 22. $\left.8^{\circ} \mathrm{W}\right)$ USGT 10-12 (17.4 N $\left.24.5^{\circ} \mathrm{W}\right)$ USGT11-24 (17.4'N 24.5'W)
North Pacific

$\delta^{66} \mathrm{Zn}_{\text {LYON Muc }}(\%)$

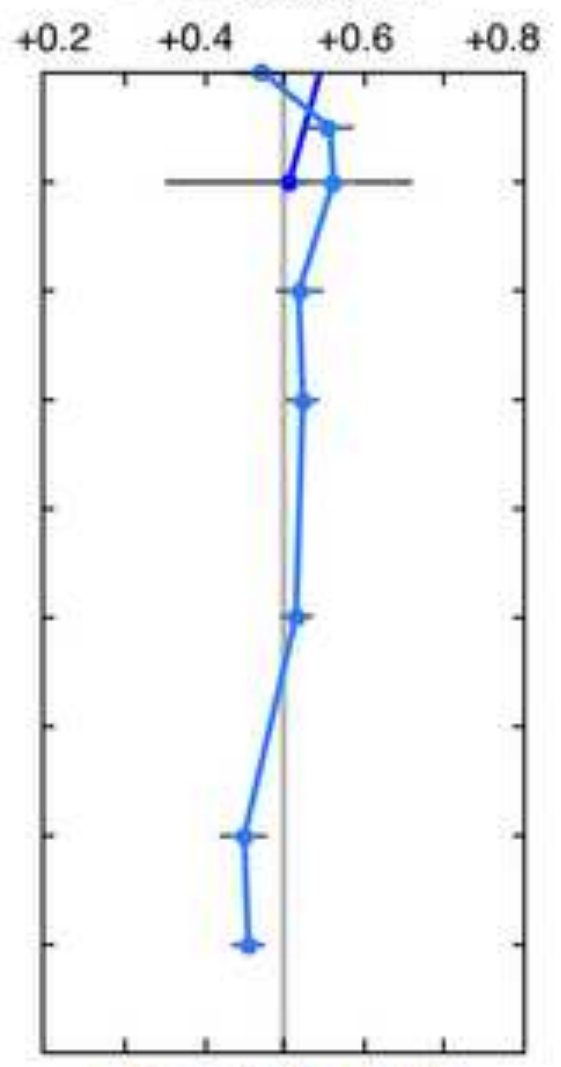

SAFe $\left(30^{\circ} \mathrm{N} 140^{\circ} \mathrm{W}\right)$ N.Pac. $\left(47^{\circ} \mathrm{N} 170.5^{\circ} \mathrm{W}\right)$ 
Figure 5

a) Fe (data from John et al,, 2012)
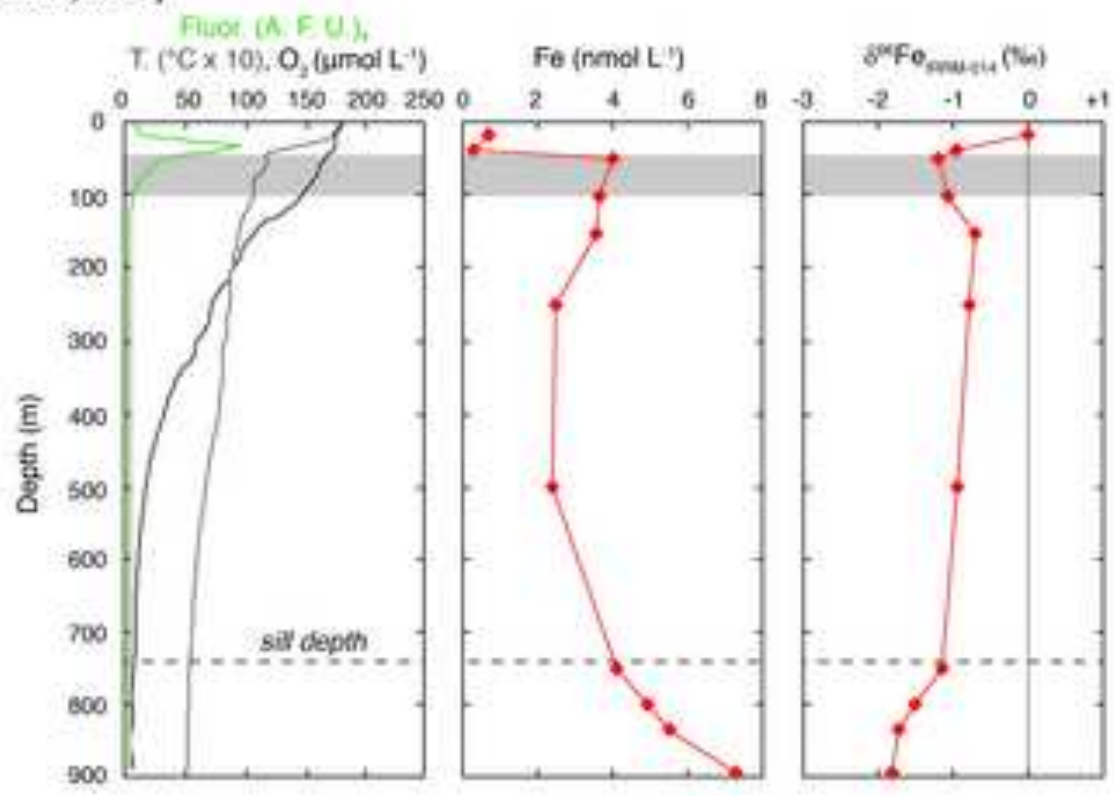

b) Cd

$0,($ imoi L')

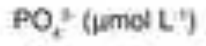

Cd ( $\mathrm{nmol} \mathrm{kg}$ ')

$8^{r}+C_{\text {man }} x \rightarrow(\mathrm{N})$

Cd:
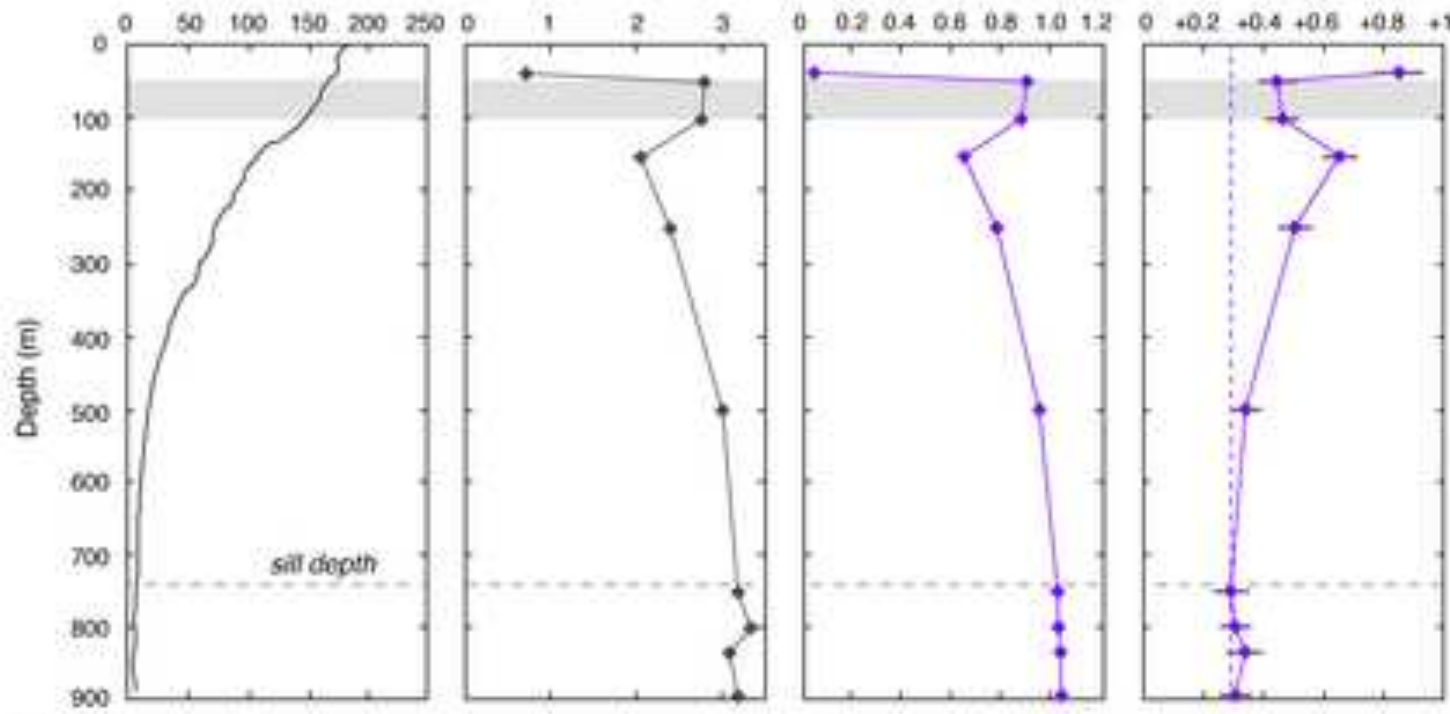

a) $\mathrm{Zn}$

Salinity (P.S.U.)

Sil (umol L')

$\mathrm{Zn}$ (nmol $\mathrm{kg}^{-1}$ )

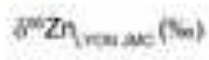
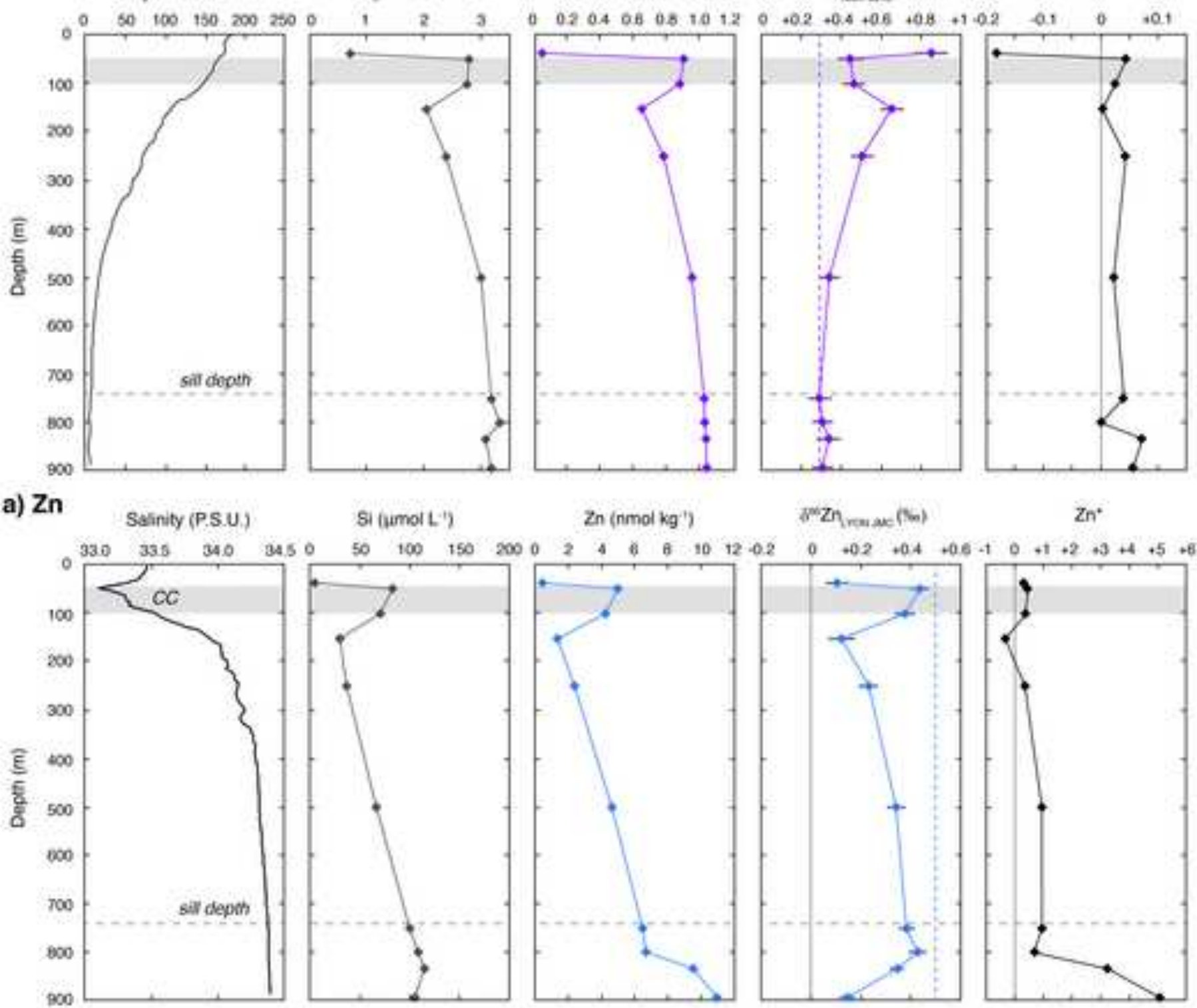

$\mathrm{Zn}^{*}$

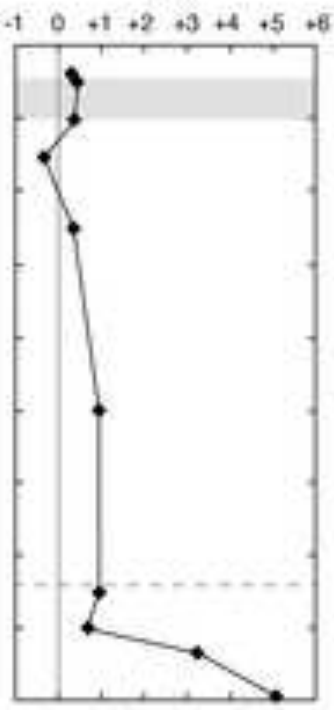

